\title{
Reversible induction of translational isoforms of p53 in glucose deprivation
}

\author{
D Khan ${ }^{1,3}$, A Katoch ${ }^{1,3}$, A Das ${ }^{2}$, A Sharathchandra ${ }^{1}$, R Lal ${ }^{1}$, P Roy ${ }^{1}$, S Das ${ }^{1}$, S Chattopadhyay ${ }^{2}$ and S Das ${ }^{\star, 1}$
}

Tumor suppressor protein p53 is a master transcription regulator, indispensable for controlling several cellular pathways. Earlier work in our laboratory led to the identification of dual internal ribosome entry site (IRES) structure of p53 mRNA that regulates translation of full-length p53 and $\Delta 40$ p53. IRES-mediated translation of both isoforms is enhanced under different stress conditions that induce DNA damage, ionizing radiation and endoplasmic reticulum stress, oncogene-induced senescence and cancer. In this study, we addressed nutrient-mediated translational regulation of p53 mRNA using glucose depletion. In cell lines, this nutrient-depletion stress relatively induced p53 IRES activities from bicistronic reporter constructs with concomitant increase in levels of p53 isoforms. Surprisingly, we found scaffold/matrix attachment region-binding protein 1 (SMAR1), a predominantly nuclear protein is abundant in the cytoplasm under glucose deprivation. Importantly under these conditions polypyrimidine-tractbinding protein, an established p53 ITAF did not show nuclear-cytoplasmic relocalization highlighting the novelty of SMAR1-mediated control in stress. In vivo studies in mice revealed starvation-induced increase in SMAR1, p53 and $\Delta 40$ p53 levels that was reversible on dietary replenishment. SMAR1 associated with p53 IRES sequences ex vivo, with an increase in interaction on glucose starvation. RNAi-mediated-transient SMAR1 knockdown decreased p53 IRES activities in normal conditions and under glucose deprivation, this being reflected in changes in mRNAs in the p53 and $\Delta 40 p 53$ target genes involved in cell-cycle arrest, metabolism and apoptosis such as p21, TIGAR and Bax. This study provides a new physiological insight into the regulation of this critical tumor suppressor in nutrient starvation, also suggesting important functions of the p53 isoforms in these conditions as evident from the downstream transcriptional target activation.

Cell Death and Differentiation (2015) 22, 1203-1218; doi:10.1038/cdd.2014.220; published online 27 February 2015

p53 is a master transcription factor and tumor suppressor. Apart from post-translational modifications of p53 and concomitant protein-protein interactions of p53 with diverse factors, translational control of $p 53$ mRNA also plays an important role under stress conditions. ${ }^{1}$

p53 and its $\mathrm{N}$-terminally truncated isoform $\triangle 40 \mathrm{p} 53$ (also known as $\Delta N-p 53$ or p53/47) are translated by internal ribosome entry site (IRES)-mediated translation initiation from the same mRNA under different stress conditions that induce DNA damage, ionizing radiation and endoplasmic reticulum (ER) stress, oncogene-induced senescence and cancer. ${ }^{2-7}$ Thus, p53 mRNA has a dual IRES structure. ${ }^{8}$ For their function, these IRESs rely on IRES trans-acting factors (ITAFs). Polypyrimidine-tract-binding protein (PTB) was shown to have differential affinity for the two IRESs of p53 and regulated p53 IRES functions by translocating from nucleus to cytoplasm on doxorubicin-induced DNA damage. ${ }^{3}$ This PTB-mediated control of $p 53$ IRESs has been recently found to play a role in the p53-fibrillarin-rRNA methylation network. ${ }^{9,10}$ Single-nucleotide polymorphisms in p53 $5{ }^{\prime} \mathrm{UTR}^{11}$ or in the coding region of p53 IRES $^{7,11,12}$ decreased p53 IRES activity by altering PTB, MDM2 or hnRNPC1/C2 interactions with this regulatory region in p53
mRNA. Annexin A2 and PTB-associated splicing factor (PSF) proteins, putative 553 ITAFs, interact with p53 IRESs ex vivo in a stress-induced manner, showing greater association with the IRESs on thapsigargin treatment. ${ }^{13}$ An elF4G homolog, death-associated protein 5 (DAP5) was demonstrated to bind to p53 IRESs and regulate the second IRES-mediated expression of $\triangle 40 p 53$, whereas such regulation by DAP5 of the first IRES-mediated expression of $p 53$ was more subtle. ${ }^{14}$ hnRNPQ was demonstrated to bind to p53 5'UTR and control its translation efficiency. ${ }^{15}$ Apart from various ITAFs, p53 5'UTR is also known to bind several proteins such as RPL26, ${ }^{16}$ nucleolin, ${ }^{17}$ PDCD $4{ }^{18}$ and RNPC $1 .{ }^{19}$

Nutrient-limitation or starvation is also known to induce cellular stress. In Drosophila under poor nutritional conditions, FOXO (a Forkhead-box transcription factor) mediates accumulation of INR via IRES-mediated translation of the INR mRNA. ${ }^{20}$ Nutritional control of transcription/ translation via modulation of IRES activity is also exemplified by the cellular response to limited amino acid availability. ${ }^{21,22}$ Amino acid depletion induces GCN2 kinase-mediated phosphorylation of elF2a, leading to a global decrease in protein synthesis and induction of an adaptive survival program. ${ }^{21,23}$ Under this condition, IRES-mediated translation of the Cat-1 and SNAT2

\footnotetext{
${ }^{1}$ Department of Microbiology and Cell Biology, Indian Institute of Science, Bangalore, India and ${ }^{2}$ National Centre for Cell Science, Ganeshkhind, Pune, India ${ }^{*}$ Corresponding author: S Das, Department of Microbiology and Cell Biology, Indian Institute of Science, Bangalore 560012, India. Tel: +91 8022932886 ; Fax: +91 80 2360 2697; E-mail: sdas@mcbl.iisc.ernet.in

${ }^{3}$ These authors contributed equally to this work.

Abbreviations: IRES, internal ribosome entry site; ER, endoplasmic reticulum; ITAFs, IRES trans-acting factors; R-Luc, Renilla luciferase; F-Luc, firefly luciferase; CHX, cycloheximide; TAD I, transactivation domain; 14A, pGFP-hp-p53-5'UTR-cDNA; 14A-M1 plasmid, pGFP-hp-p53-5'UTR-(A252G/T253C/G254T)-cDNA; 14A-M2 plasmid, pGFP-hp-p53-5'UTR(A135T)-cDNA; mSMAR1, mouse SMAR1; SMAR1Tg, SMAR1 transgenic; EMSA, electrophoretic mobility shift assay; DOXO, doxorubicin Received 07.3.14; revised 13.11.14; accepted 14.11.14; Edited by M Oren; published online 27.2.15
} 
mRNAs occur, ${ }^{24,25}$ thus preparing cells to transport amino acids once they become available. Methionine synthase, a key enzyme that clears intracellular homocysteine, is induced by its cofactor, vitamin B12, at a translational level through an IRES in the 5 'UTR of the MRNA. $^{26}$ In response to glucose deprivation, haploid Saccharomyces cerevisiae cells dramatically downregulate translation of most cellular messages, ${ }^{27,28}$ but several yeast genes required for invasive growth, a developmental pathway induced by nutrient limitation, contain potent IRESs. ${ }^{29}$ Serum starvation of mammalian cell cultures showed induction of $\mathrm{Bcl}-2 \mathrm{IRES}^{30}$ and activated translation of XIAP mRNA. ${ }^{31}$ IRES-mediated translation of $p 27^{K i p 1} \mathrm{mRNA}$ contributes to maintenance of $\mathrm{G} 1$ phase of the cell cycle and the expression of $\mathrm{p} 27^{\mathrm{Kip} 1}$ was found to be iron sensitive. . $^{32,33}$

These studies reveal a novel aspect of activation of IRESmediated translation of eukaryotic mRNAs due to nutrient shortage, resulting in the synthesis of proteins essential for cell survival or apoptosis. Thus, it is important to investigate IRES activity of $p 53$ mRNA in nutrient-deprived conditions. In the current study, results suggest that glucose depletion relatively induces p53 IRES activity as seen in bicistronic reporter assays. There are reports that have implicated p53 protein in binding its own RNA. ${ }^{34}$ The E3-ubiquitin ligase MDM2 is a well-known target of p53, forming a feedback loop and regulating p53 degradation. Interestingly, MDM2 has also been shown to interact with coding sequence of the IRES in p53mRNA. ${ }^{12,35,36}$ A recent work suggested stress-dependent formation of a ternary complex of three proteins: p53, MDM2 and SMAR $1,{ }^{37}$ another transcriptional target of p53 that can modulate p53 transactivation potential. ${ }^{37,38}$ We now find that SMAR1, a predominantly nuclear protein becomes abundant in the cytoplasm under glucose deprivation. Thus glucose deprivation, a form of nutrient-depletion stress, can induce p53 IRESs and also increases cytoplasmic abundance of SMAR1 that in turn binds to p53 IRESs, indicating the role of SMAR1 in controlling translation of p53 isoforms. Also, this increase in p53 isoforms is reversible suggesting that transient glucose or dietary deprivation can impinge reversibly on p53 signaling as suggested by p53-target transactivation.

\section{Results}

Glucose deprivation increases p53 IRES activity. p53-null H1299 cells were transfected with luciferase bicistronic constructs containing p53 1-251 RNA in the intercistronic region. ${ }^{7,8,11}$ Control cells and glucose-starved cells were harvested $4,8,20$ and $30 \mathrm{~h}$ post-transfection. There was a consistent increase in the relative IRES activity at all these time points following glucose deprivation, with a 1.7-fold increase in activity by $20 \mathrm{~h}$ (Figure 1a, H1299 panel and Supplementary Table S1). Similar experiments were performed on A549 cells (with endogenous p53) and results corroborated the observation in $\mathrm{H} 1299$ cells. The relative IRES activity increased by 2.3 -fold by $20 \mathrm{~h}$ and elevated IRES activity was maintained at $30 \mathrm{~h}$ following glucose deprivation in A549 cells (Figure 1a, A549 panel and Supplementary Table S2). In both $\mathrm{H} 1299$ and A549 cells, the relative increase in IRES activity also reflects a concomitant decrease in cap-dependent translation of Renilla luciferase, this being more evident in the p53-positive A549 cells, as glucose deprivation induces elF2 $a$ phosphorylation. ${ }^{39}$ As evident from these readings, fold decrease in cap-dependent translation (R-Luc) is much higher compared to fold decrease in capindependent translation (F-Luc), that can be interpreted as a situation wherein the IRES function maintains the translation of F-Luc. To address the relative effect of glucose deprivation on p53 IRES1 and IRES2, bicistronic plasmids containing the first (1-134) or second (135-251) IRES RNA module of p53 were transfected into $\mathrm{H} 1299$ cells. Similar experimental regimen as above showed that at $30 \mathrm{~h}$ of glucose deprivation, the activity of first IRES region increased 2.4-fold (Figure 1b and Supplementary Table S3) whereas that of second IRES module increased 1.7-fold (Figure 1c and Supplementary Table S3), a consistent increase at all the time points being a common feature of both IRESs. The response to glucose deprivation was IRES specific, relative activity of VEGF IRES (Figure 1d and Supplementary Table S4), but not HIF1a or HCV IRES (Figures $1 \mathrm{e}$ and $\mathrm{f}$ and Supplementary Tables S5 and S6, respectively), was higher in these conditions.

For studying the effect of glucose deprivation on p53 IRES-mediated translation, pGFP-hp-p53-5'UTR-cDNA (14A) plasmid that expresses both p53 and $\triangle 40$ p53 by IRESmediated translation was transfected in $\mathrm{H} 1299$ cells followed by glucose deprivation for $8 \mathrm{~h}$ and $30 \mathrm{~h}$. There was discernible increase in the steady-state levels of both the isoforms in these time points (Figure 1g). To investigate whether such an increase was due to greater stability of these isoforms after glucose deprivation, time dependent of cycloheximide ( $\mathrm{CHX}$, translation-initiation blocker) treatment was done $30 \mathrm{~h}$ postglucose deprivation. Interestingly, the induction in the steadystate levels of p53 and $\Delta 40 p 53$ (Figure $1 \mathrm{~h}$, lane 1 versus 4 ) was completely abrogated post-CHX treatment (Figure $1 \mathrm{~h}$, lanes 5 and 6) suggesting that such induction is possibly at the level of translation initiation, which is IRES mediated in this experimental setting. Downstream to glucose-deprivationmediated p53 induction, p21 promoter was found to be significantly activated in a luciferase reporter assay (Figure 1i).

The first transactivation domain (TAD-I) of p53 protein is the docking site for MDM2-E3 ligase that ubiquitinylates p53 and targets it for degradation. ${ }^{40}$ It was thus imperative to delineate if inhibition of MDM2 function on glucose deprivation results in elevated p53 stability. Two constructs as shown in Figure 1j were used, one would produce only p53 as second ATG was mutated (pGFP-hp-p53-5'UTR-(A252G/T253C/G254T)-cDNA or 14A-M1 plasmid), while the other would produce only $\triangle 40$ p53 as the first ATG was mutated (pGFP-hp-p53-5'UTR (A135T)-cDNA or 14A-M2 plasmid), both plasmids would employ entire (1-251) IRES to direct synthesis of the protein. When cells were deprived of glucose for 8 or $30 \mathrm{~h}$, there was increase in the levels p53 and also of $\Delta 40$ p53 (Figure 1j). Since, $\triangle 40 p 53$ isoform lacks TAD-I and cannot bind MDM2, increase in its levels occurs apparently rules out possible physical participation of MDM2 in elevating steady-state levels of p53 isoforms on glucose deprivation. This also suggests that apart from any increase in protein stability that might be attributed to glucose-starvation-induced 
full-length p53 levels, translation of p53 mRNA (which is IRES mediated in this experiment) is also essential for such induction.
SMAR1 knockdown inhibits p53 IRES function. In order to determine whether SMAR1 participates in IRES-mediated translation of p53 mRNA in a more direct way, the effect of

\section{a}
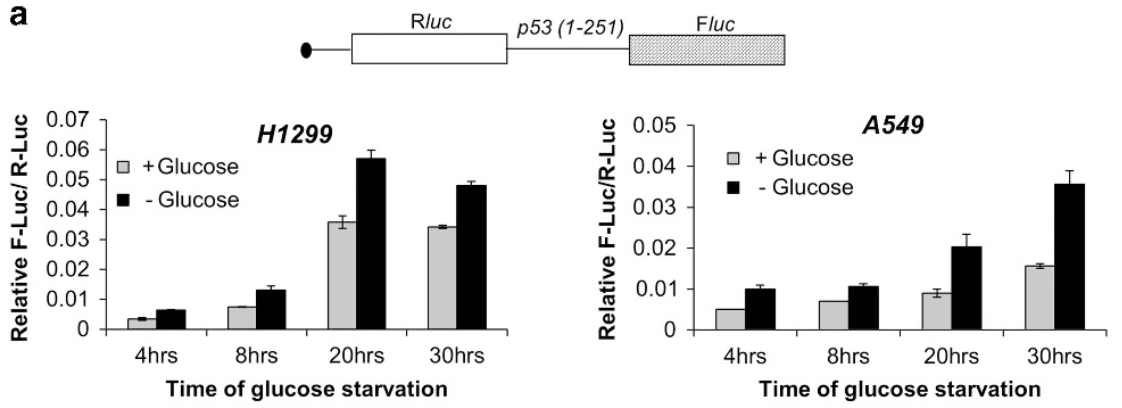

b

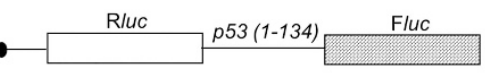

C
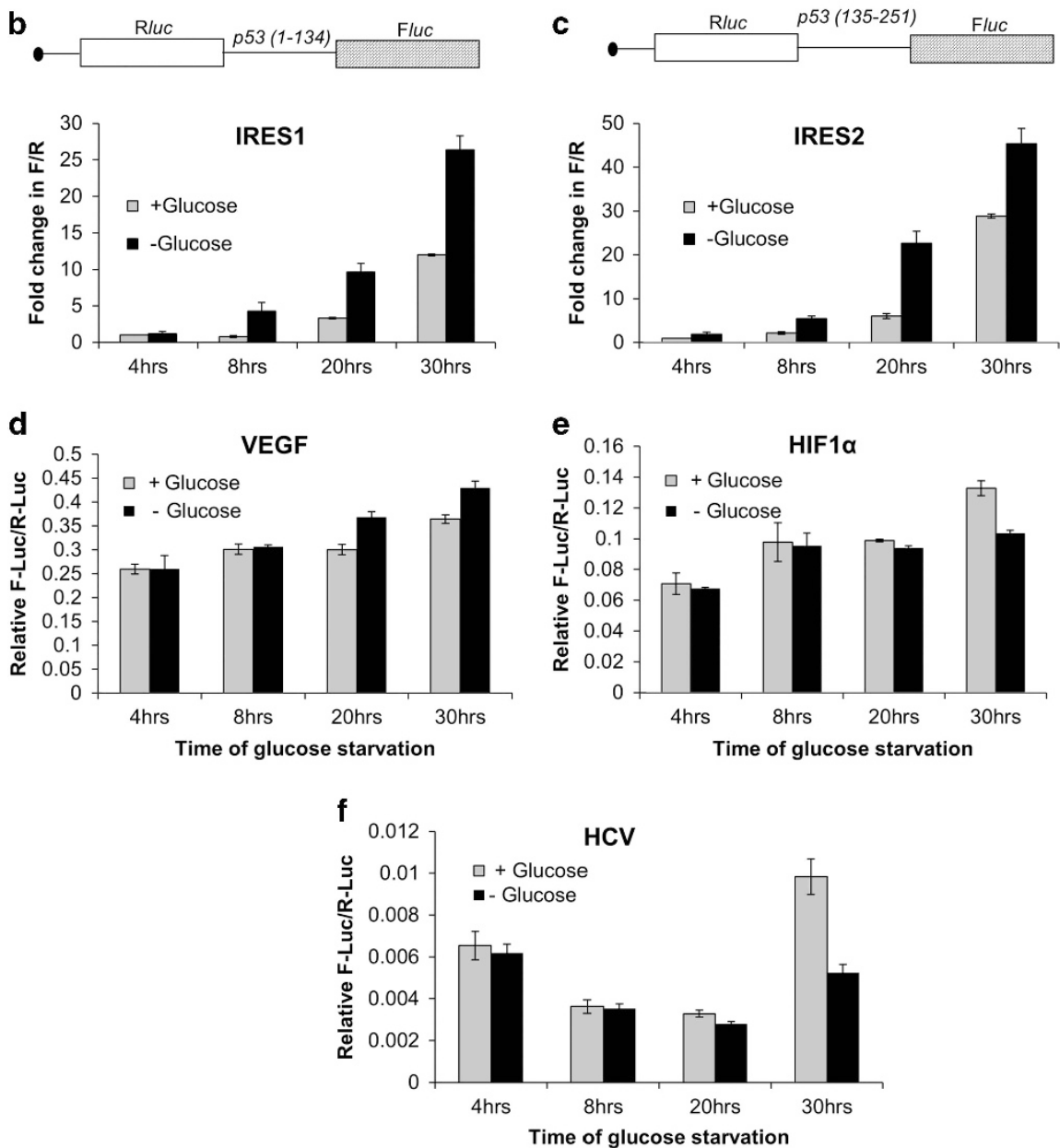

Figure 1 Glucose deprivation induces p53 IRES activity. (a) Schematic representation of the bicistronic construct pRp53(1-251)F that contains 1-251 IRES RNA. Relative IRES activity is represented by the Fluc/Rluc ratio at various time points for $\mathrm{H} 1299$ and $\mathrm{A} 549$ cells, $n=6$. (b) Schematic representation of the bicistronic construct pRp53(1-134)F that contains the first IRES of p53, corresponding to the 134nt in the 5'UTR. Fold change in Fluc/Rluc ratio as measure of IRES activity, from fourth hour unstarved cells set at unit, at various time points in $\mathrm{H} 1299$ cells, $n=6$. (c) Schematic representation of the bicistronic construct pRp53(135-251)F that contains the second IRES of p53, corresponding to the first 117nt of the coding sequence. Fold change in Fluc/Rluc ratio as measure of IRES activity, from fourth hour unstarved cells set at unit, at various time points in H1299 cells, $n=6$. (d-f) Relative VEGF (d), HIF1 $\alpha$ (e) and HCV (f) IRES activity is represented by the Fluc/Rluc ratio at various time points for H1299 cells, $n=6$ for each. (g) Western blot from H1299-cell extracts transfected with $14 \mathrm{~A}$ plasmid that expresses both $\mathrm{p} 53$ and $\Delta 40 \mathrm{p} 53$ by IRES-mediated translation, followed by glucose deprivation for 8 and $30 \mathrm{~h}$. Graphs show $\mathrm{p} 53$ and $\Delta 40 \mathrm{p} 53$ levels normalized to actin. (h) Western blot from $\mathrm{H} 1299$-cell extracts transfected with $14 \mathrm{~A}$ plasmid that expresses both p53 and $\Delta 40 \mathrm{p} 53$ by IRES-mediated translation, followed by glucose deprivation for $30 \mathrm{~h}$ and $50 \mu \mathrm{g} / \mathrm{ml}$ cycloheximide (CHX) treatment for next 0,60 and $120 \mathrm{~min}$. Graphs show lane-wise p53 and $\Delta 40 \mathrm{p} 53$ levels normalized to actin. (i) Luciferase reporter assay for p21-promoter transactivation from H1299 cells after $24 \mathrm{~h}$ of pGFP-hp-p53-5'UTR-cDNA plasmid transfection and $8 \mathrm{~h}$ of glucose deprivation, $n=6$. Schematic representation of p21(WAF1) promoter-firefly luciferase and CMV-Renilla luciferase, latter acting as transfection control, are shown. Western blot in inset shows induction of p53 and $\Delta 40 \mathrm{p} 53$ levels after $8 \mathrm{~h}$ of glucose deprivation from same lysates. (j) Western blot of H1299-cell extracts transfected with $14 \mathrm{~A}-\mathrm{M} 1$ or 14A-M2 plasmid (see Results section for description). Cells were starved of glucose for 8 and $30 \mathrm{~h}$ 


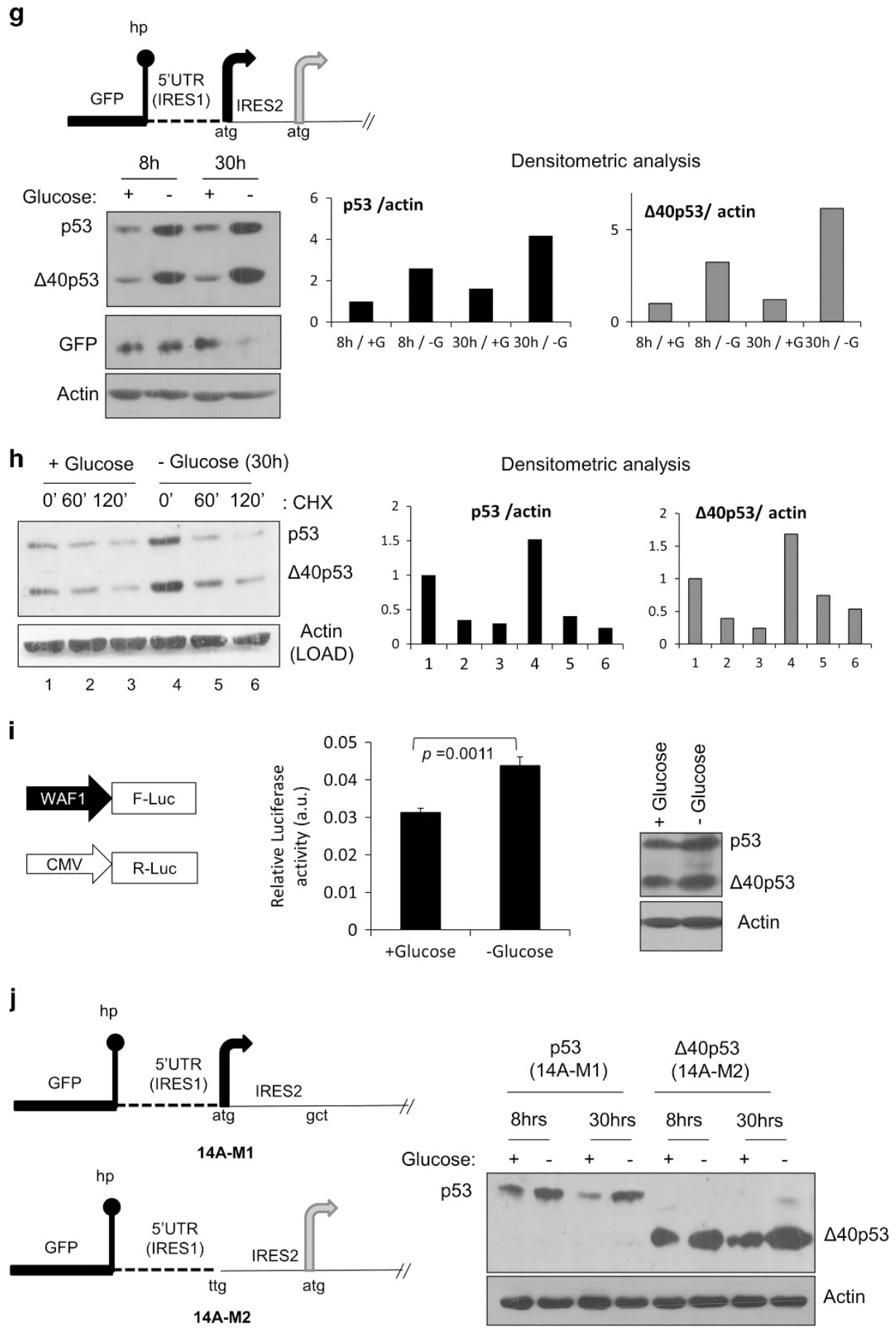

Figure 1 Continued

SMAR1 knockdown on the IRES-mediated expression of p53 isoforms from pGFP-hp-p53-5'UTR cDNA was assessed. An siRNA-mediated-dose-dependent decrease was seen in the levels of p53 and $\Delta 40$ p53 (Figure 2a) but not in cap-dependent $\beta$-galactosidase expression (Figure $2 a$ inset), suggesting that knocking down SMAR1 specifically affected the IRES-dependent synthesis of p53 isoforms. Similar siRNA-mediated knockdown experiments with pRp53 (1-251)F bicistronic construct, representing both modules of p53 IRES is needed for complete IRES functionality in $\triangle 40$ p53 synthesis, ${ }^{3,8}$ decreased IRES activity by nearly $30 \%$ (Figure 2b and Supplementary Table S7) and SMAR1 knockdown was checked by immunoblotting (Figure $2 \mathrm{~b}$, inset). HCT116-p53 $3^{+/+}$colon carcinoma cells (like A549 non-small-cell lung carcinoma cells used) also have endogenous levels of $\mathrm{p} 53$ and $\triangle 40 \mathrm{p} 53$, in which expression of the shorter isoform is completely IRES dependent. siRNAmediated knockdown of SMAR1 could downregulate $\triangle 40 p 53$ 
levels in these cells (Supplementary Figure S8A). In these cells also, there was a dose-dependent decrease in IRES activity from pRp53(1-251)F bicistronic construct as well (Supplementary Figure S8B and Supplementary Table S8C). To validate the RNA-interference results, two stable cell lines were established by puromycin selection. H1299-S3 cells stably expressed the shRNA for SMAR1, while H1299-NS cells expressed a non-targetting shRNA; IRES-mediated expression of p53 and $\triangle 40$ p53 was lesser in H1299-S3 cells (Figure 2c). We also checked p53 and $\Delta 40$ p53 levels on overexpressing the pcDNA p53 mammalian vector (5'UTR+cDNA; Supplementary Figure S9A) and 14A (Supplementary Figure S9B) in H1299-NS and H1299-S3 cells, in the presence and absence of DNA-damaging agent doxorubicin; results suggest that steady-state levels of both isoforms depend on SMAR1 levels. Interestingly, SMAR1 levels were also induced on DNA damage. However, it should be noted that SMAR1 can interact with full-length p53 in its TAD1 and positively regulate its stability ${ }^{37}$ and hence the levels of the full-length isoform will depend on both translation and stability.

Caspase $3 / 7$ activation was lessened even in the presence of p53 and $\triangle 40 p 53$ if SMAR1 was knocked down for $48 \mathrm{~h}$ (Figure 2d). The reduction in $\triangle 40 p 53$ expression due to SMAR1 knockdown also impaired its ability to induce transcription of downstream target genes. 14-3-3 $\sigma$ was recently reported as a preferential $\triangle 40 p 53$ target gene.,14 Expressing $\triangle 40 \mathrm{p} 53$ from the $14 \mathrm{~A}-\mathrm{M} 2$ plasmid resulted in a $70 \%$ increase in 14-3-3o mRNA in H1299-NS cells (Figure 2e). However, SMAR1 knockdown greatly compromised the induction of $14-3-3 \sigma$ mRNA with only about $17 \%$ increase in the H1299-S3 cells, suggesting that SMAR1 is required for $\triangle 40 p 53-m e d i a t e d$ transactivation (Figure 2e).

We posed the question that if proteasomal degradation was inhibited by MG132 treatment (60 min) in H1299-S3 cells, will that alleviate SMAR1-knockdown-mediated repression of p53 and $\triangle 40 p 53$ expression. We used two constructs for this study (Figure 2f): one that would express both isoforms (14A), while another that would express only $\triangle 40$ p53 (14A-M2). In either case, expression of p53 isoforms would be solely IRES mediated. On MG132 treatment after SMAR1 knockdown, there was no de-repression in the expression of p53 isoforms from either construct, suggesting that the role of SMAR1 is not at the level of protein degradation (Figure 2f). SMAR1 is known to bind to full-length p53 at 14-16 amino acids that reside within TAD-I. ${ }^{37}$ Since, SMAR1 knockdown decreased p53 as well as $\triangle 40 p 53$ levels expressed from different constructs and $\triangle 40 p 53$ lacks TAD-I, SMAR1 seems to have functions that are independent of TAD-I interaction also. A plausible explanation is that SMAR1 is indeed essential for IRES-dependent translation of p53 and $\triangle 40 p 53$.

p53-MDM2 protein interaction is well documented in the scientific literature. Another protein SMAR1 was found to form a ternary complex with p53-MDM2. ${ }^{37}$ As a proof of concept that SMAR1 homologs can bind p53 RNA, 6X-His-tagged mouse SMAR1 (BANP) was purified (Supplementary Figure S10A) and found to interact with p53 (1-251) IRES RNA in direct as well as competition RNA-protein UV-crosslinking assay (Supplementary Figures S10B and D), under native conditions in RNA-EMSA (Supplementary Figure S10E) and also with the 1-134 and 135-251 regions of p53 IRES RNA in filter-binding assays (Supplementary Figure S10F).

Intracellular redistribution of SMAR1 on glucose deprivation. Surprisingly, SMAR1 was seen to be redistributed in $\mathrm{H} 1299$ cells on glucose deprivation in immunofluorescence experiments. H1299 cells were starved of glucose for 4, 8 and $30 \mathrm{~h}$, the same points in time when relative IRES activities of p53 mRNA increase. By $8 \mathrm{~h}$, the nuclear SMAR1 was remarkably depleted with increase in cytoplasmic levels as compared to control cells at this time point (Figure 3a). However, by $30 \mathrm{~h}$ control cells and glucose-starved cells had nearly similar amounts of nuclear SMAR1 but there was more SMAR1 in the cytoplasm for the latter (Figure 3a). SMAR1 is a predominantly nuclear protein and undergoes cytoplasmic to nuclear relocalization under genotoxic stress. ${ }^{41}$ FACS studies demonstrated that glucosedeprivation-driven intracellular redistribution of SMAR1 in the cytoplasm occurred without any cues from cell-cycle changes, as the cell-cycle profiles at 4,8 and $30 \mathrm{~h}$, for control and experimental monolayer cultures were nearly identical, asynchronous and devoid of any cell-cycle arrest (Supplementary Figure S11). PTB is a very well-established ITAF for p53 IRESs and under the experimental conditions, it failed to show nuclear-cytoplasmic relocalization like SMAR1 under glucose deprivation (Figure 3b).

Increased expression of p53 and $\Delta 40$ p53 under glucose deprivation needs SMAR1. H1299-NS and H1299-S3 cells were transfected with 14A plasmid and these cells were glucose starved for $8 \mathrm{~h}$. As expected, IRES-dependent expression of p53 and $\Delta 40$ p53 were lesser in H1299-S3 cells compared to H1299-NS cells (Figure 4a). Interestingly, glucose-starvation-mediated induction of the isoform levels was remarkably abrogated in the H1299-S3 cells indicating that SMAR1 is essential for such a translational induction. For studying the effect of glucose deprivation on $\triangle 40 p 53$ alone, a similar experiment was performed with 14A-M2 plasmid and the results corroborated the essentiality of SMAR1 for glucose-starvation-mediated induction in the synthesis of $\triangle 40$ p53 (Figure 4b). Confirming our hypothesis, there was no decrease in $\triangle 40 p 53$ levels on SMAR1 knockdown or induction on glucose deprivation when this isoform alone was expressed in a cap-dependent manner without any IRES ( $\triangle$ IRES- $\triangle 40$ p53 plasmid; Figure 4c). Similarly, dual-luciferase experiments with bicistronic plasmids carrying the first (1-134) or second (135-251) IRES or with (1-251) IRES in the intercistronic region confirmed that SMAR1 is necessary for induction of IRES activity when cells are starved of glucose (Figures 4d-f; Supplementary Table S12). The expression of VEGF IRES was relatively increased on glucose deprivation, however, the expression from VEGF (Supplementary Figure S15) and HIF1a IRESs (Supplementary Figure S16) was seen to be independent of SMAR1 knockdown. Steady-state mRNA levels of three p53 transcription targets, p21, Mdm2 and TIGAR were checked in the NS and S3 cells under glucose deprivation (Figure $4 \mathrm{~g}$ ). There was an induction of all three mRNAs in NS cells but not in S3 cells, except for p21 at $30 \mathrm{~h}$ of starvation in the latter. Immunoblots for concomitant p53, $\triangle 40$ p53 and SMAR1 levels are also shown (Figure $4 \mathrm{~g}$ ). 


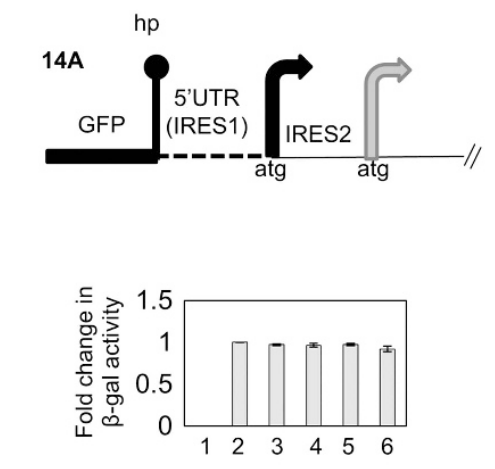

b
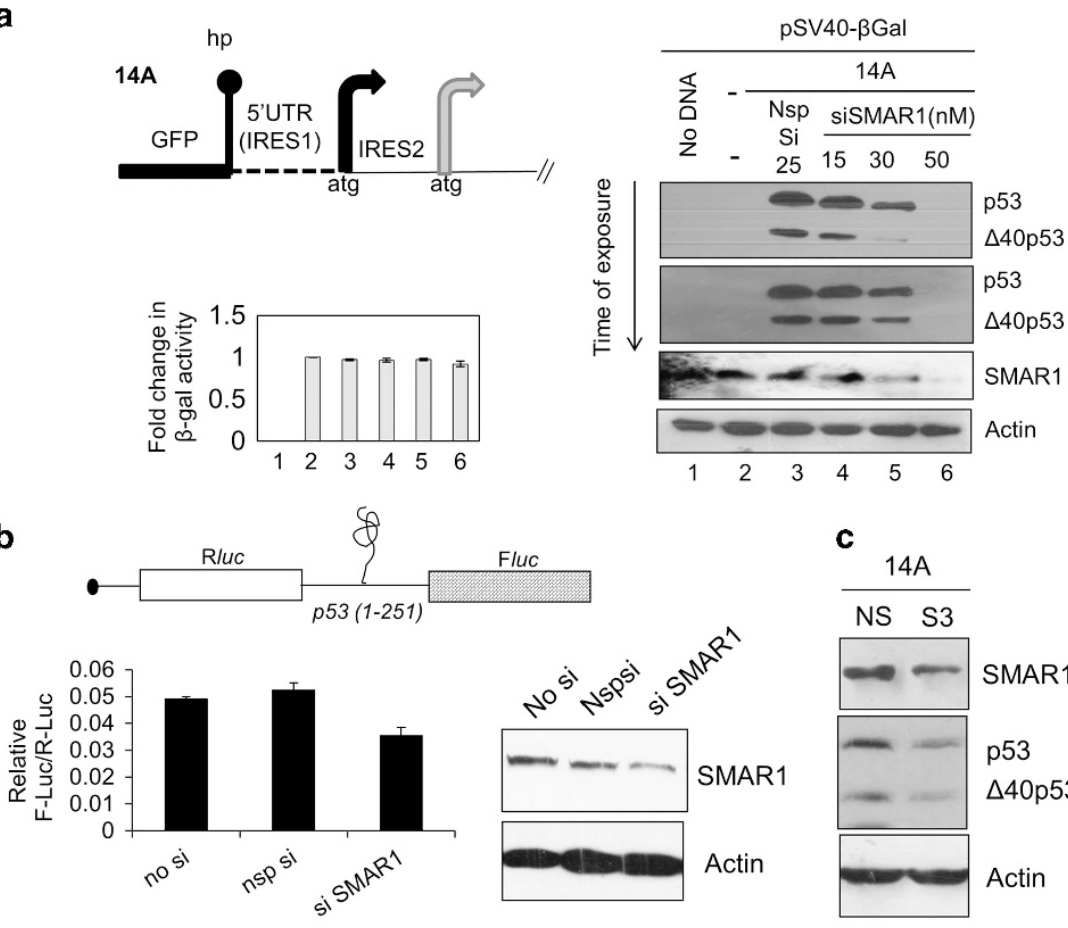

d

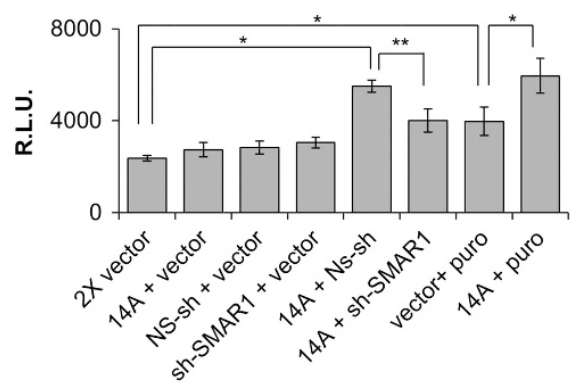

f
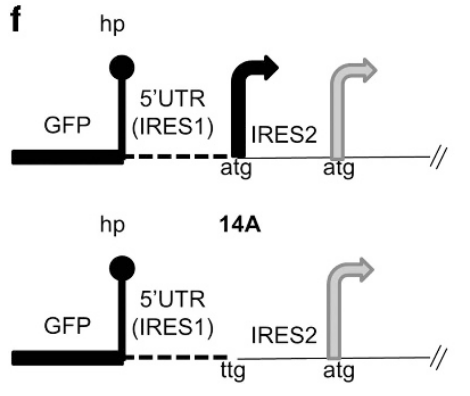

14A-M2
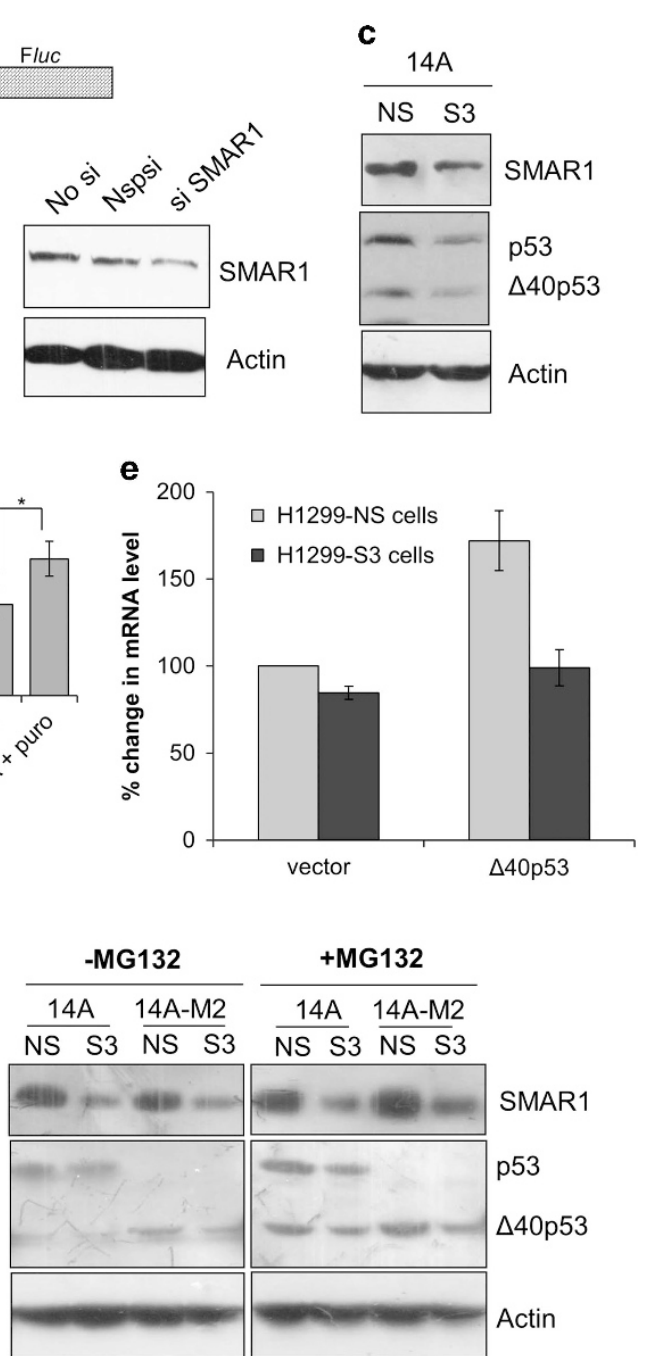

Figure 2 SMAR1 knockdown inhibits p53 IRES function. (a) Western blot of H1299-cell extracts co-transfected with pGFP-hp-p53-5'UTR-cDNA plasmid (14A, shown in schematic), pSV40- $\beta$-galactosidase plasmid (transfection and cap-dependent translation control) and non-targetting (Nsp) or SMAR1 siRNA. Inset shows fold change in $\beta$ galactosidase activity in each of the experimental conditions (1-6), $n=3$. (b) Dual-luciferase reporter assay for relative IRES activity from pRp53(1-251)F plasmid, represented by the Fluc/Rluc ratio, on SMAR1 knockdown in $\mathrm{H} 1299$ cells, $n=9$. Immunoblot in inset shows knockdown of SMAR1 in same lysates. (c) Puromycin-selected H1299 cells with stable non-targetting (NS) or SMAR1 (S3) shRNA expression were transfected with pGFP-hp-p53-5'UTR-cDNA plasmid. Western blot was done $48 \mathrm{~h}$ post-transfection. (d) Caspase $3 / 7$ activation assay in $\mathrm{H} 1299$ cells following SMAR1 knockdown in the presence of pGFP hp-p53-5'UTR cDNA (14A plasmid). Puro, puromycin ( $2 \mu \mathrm{g} / \mathrm{ml}, 24 \mathrm{~h}$ ) used as positive control for caspase induction and apoptosis. Experiment performed $48 \mathrm{~h}$ post-transfection, $n=3$. (e) $\Delta 40 \mathrm{p} 53$ target 14-3-3 $\sigma$ mRNA levels as measured by qRT-PCR in H1299-NS and H1299-S3 cells transfected with pGFP-hp-p53-5'UTR(A135T)-cDNA (14A-M2) plasmid, $n=9$. (f) Western blot of H1299-NS- and H1299-S3-cell extracts that were transfected with pGFP-hp-p53-5'UTR-cDNA (14A) or pGFP-hp-p53-5'UTR(A135T)-cDNA (14A-M2) plasmid. Proteasomal degradation inhibitor MG132 (10 $\mu$ M) was added $1 \mathrm{~h}$ before harvesting. Western blot was done on same gel and membrane; results are shown at same exposure 

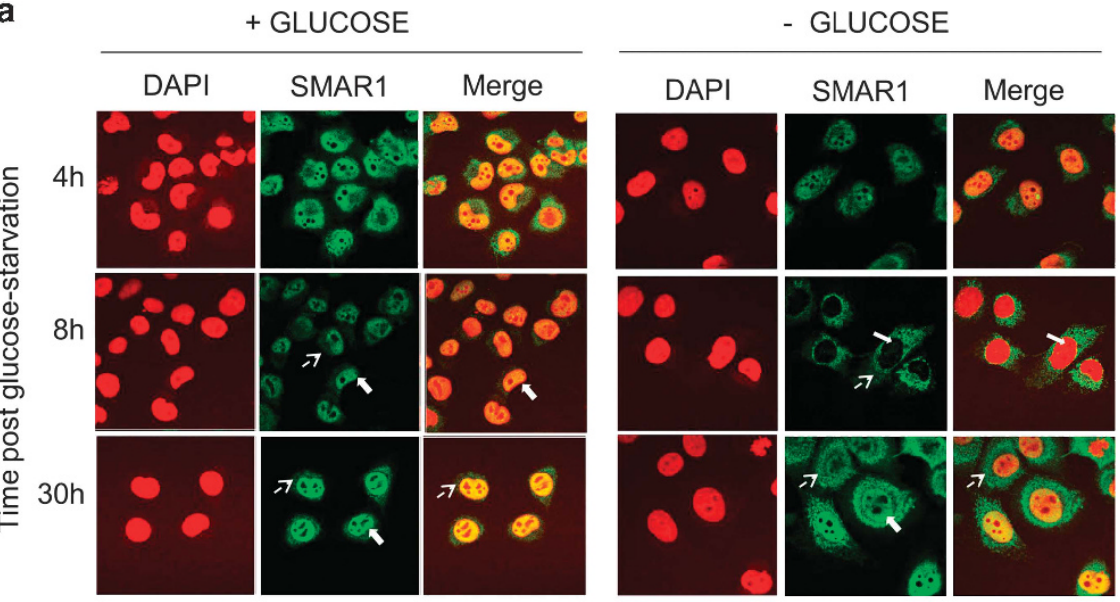

b

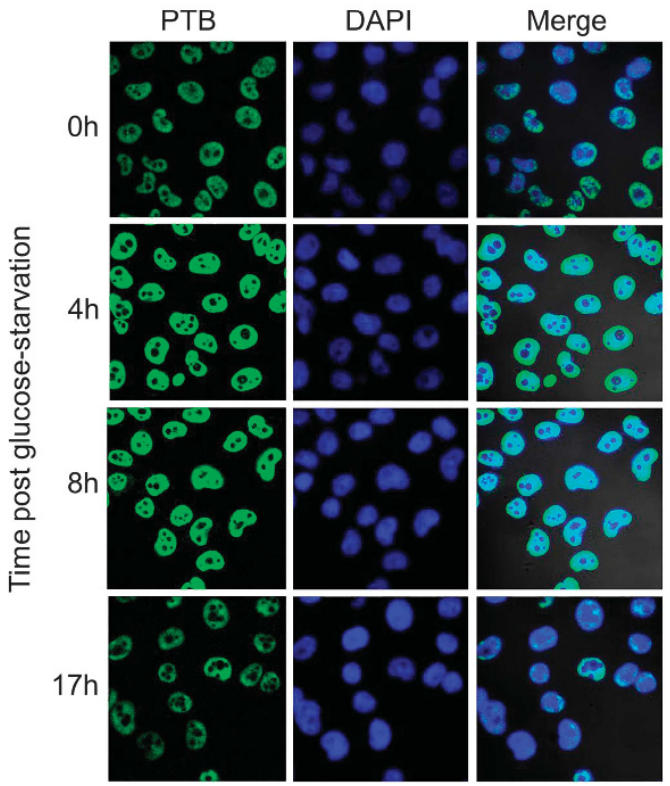

Figure 3 Localization of SMAR1 and PTB after glucose deprivation (a) Intracellular redistribution of SMAR1 on glucose deprivation. Anti-SMAR1 antibody was used in indirect immunofluorescence assay on asynchronous $\mathrm{H} 1299$ cells starved of glucose for 4,8 and $30 \mathrm{~h}$ and compared to unstarved cells at same time points. Dashed and solid arrows indicate cytoplasmic and nuclear localization of SMAR1, respectively. Fluorescently labeled secondary antibody was used and visualized by Zeiss LSM microscope at x60 objective. SMAR1 is shown in green and DAPI (nucleus) in red, whereas SMAR1 and DAPI merge is shown in yellow. (b) PTB does not relocalize to the cytoplasm on glucose deprivation. Anti-PTB antibody was used in indirect immunofluorescence assay on asynchronous $\mathrm{H} 1299$ cells starved of glucose for the indicated time points. Fluorescently labeled secondary antibody was used and visualized by Zeiss LSM microscope at x60 objective. PTB is shown in green and DAPI (nucleus) in blue, whereas PTB and DAPI merge is shown in cyan

In A549 cells, changes in $\Delta 40$ p53 levels reflect capindependent-IRES-mediated translation of this isoform. . $^{3,14}$ Owing to glucose deprivation, there was an increase in $\triangle 40 \mathrm{p} 53$ levels at $30 \mathrm{~h}$ and this was confirmed with two different antibodies (Figure 5a). p53 mRNA levels do not change significantly over this time period (Supplementary Figure S17A). In A549 (Figure 5b) and HCT116 cells (Figure 5c), mRNA levels of $p 21$ (a preferential p53 target) and SFN (a preferential $\Delta 40 \mathrm{p} 53$ target) increases significantly after $30 \mathrm{~h}$ of glucose depletion. In A549 as well as in hepatic HepG2 cells, steady-state level of SMAR1 protein was found to be increased on glucose deprivation (Figure $5 d$ ). However, when SMAR1 was depleted using siRNA, $\triangle 40 p 53$ expression was almost abrogated on glucose starvation (Figure $5 e$ ).
This indicates that SMAR1 is necessary for $\Delta 40 p 53$ expression under such conditions. The ex vivo interaction of p53 IRES was addressed by quantitative immunoprecipitation experiments. From A549 cells, RNA-protein complexes were immunoprecipitated with anti-SMAR1 antibody. The ITAF PTB, which was shown to bind p53 IRESs, ${ }^{3}$ served as a positive control (Figure 5f, anti-PTB bars). RT-qPCR analysis of the SMAR1-immunoprecipitate-associated RNA showed the presence of the RNA corresponding to 1-251 IRES, over and above than that from RNA-protein complexes immunoprecipitated by the IgG-isotype antibody, in non-starved cells (Figure 5f). There was an apparent increase in the amount of RNA pulled down by anti-SMAR1 antibody from glucosestarved A549 cells (Figure 5f). A similar experiment was 
a

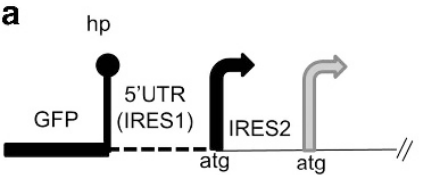

$14 \mathrm{~A}$
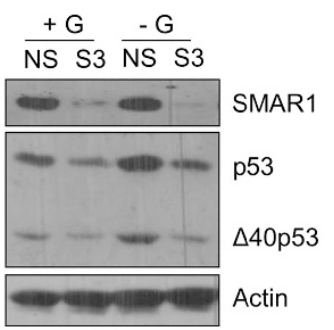

b

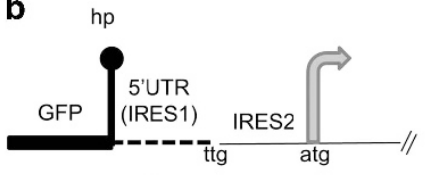

14A-M2

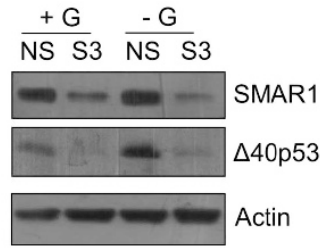

C

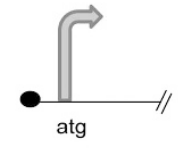

$\triangle$ IRES- $\triangle 40 \mathrm{p} 53$

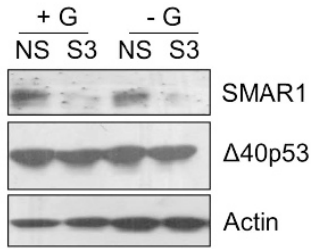

d

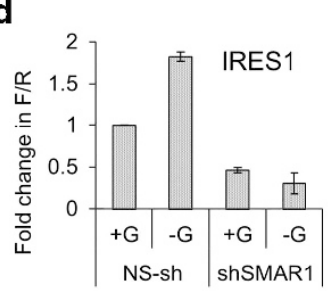

e

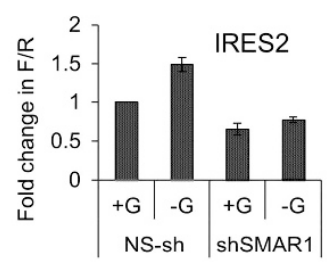

f

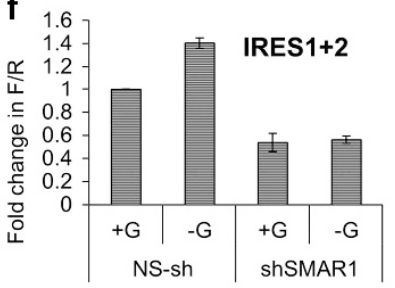

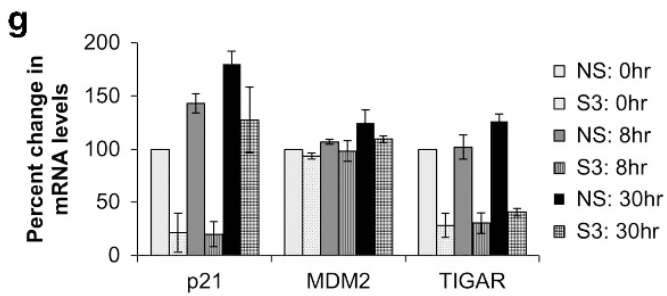

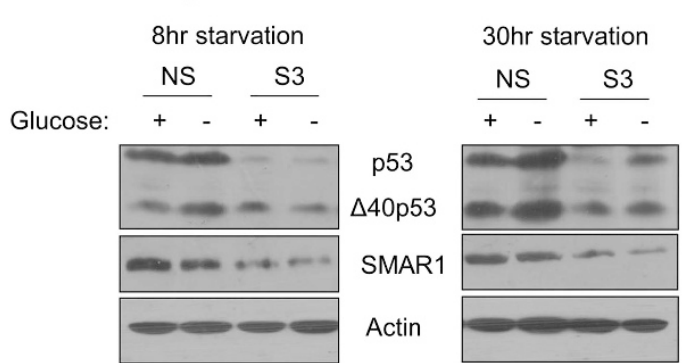

Figure 4 Increased IRES-dependent expression of p53 and $\triangle 40 p 53$ and downstream activation of target mRNAs under glucose deprivation is SMAR1 dependent. (a-c) Western blot analysis of H1299-NS- and H1299-S3-cell extracts transfected with pGFP-hp-p53-5'UTR-cDNA plasmid (14A in schematic; a), pGFP-hp-p53-5'UTR(A135T)-cDNA plasmid (14A-M2 in schematic; b) or $\Delta \mathrm{IRES}-\Delta 40 \mathrm{p} 53$ plasmid (c) that were glucose starved $(-\mathrm{G}$ ) for $8 \mathrm{~h}$ before harvesting, compared with unstarved (+G) cells. (d-f) Dualluciferase reporter assay for pRp53(1-134)F (IRES1, d), pRp53(135-251)F (IRES2, e) and pRp53(1-251)F (IRES1+2, f) bicistronic constructs transfected in H1299-NS and H1299-S3 cells that were glucose starved $(-G)$ for $8 \mathrm{~h}$ before harvesting, compared with unstarved $(+G)$ cells. Fold change in IRES activity (Fluc/Rluc) shown with this ratio unit normalized for unstarved H1299-NS cells, $n=6$. (g) Quantitative PCR for levels of p53-target mRNAs p21/Cip1 (CDK-interacting protein1), Mdm2 (murine double minute 2) and TIGAR (TP53-induced glycolysis and apoptosis regulator), assayed after 0,8 and $30 \mathrm{~h}$ of glucose deprivation of H1299-NS and H1299-S3 cells transfected with pGFP-hp-p535'UTR-cDNA (14A) plasmid, $n=3$. Representative immunoblots depicting SMAR1, p53 and $\triangle 40 p 53$ levels are shown

performed in p53-null H1299 cells, which were transfected with GFP-hp-5'UTR-p53-bicistronic RNA (Figure 5g). There was a clear increase in IRES RNA that was pulled down with SMAR1 in conditions of glucose deprivation as compared to normal glucose (Figure 5g, anti-SMAR1 bars). Together, these results demonstrate that SMAR1 can interact with the p53 (1-251) IRES in cells and such association apparently increases on glucose deprivation. We next investigated cellcycle progression (Figure $5 \mathrm{~h}$ ) after double-thymidine block in
NS or S3 cells transfected with pEGFP (expresses only EGFP)-, 14A (construct expresses GFP, p53a and $\Delta 40$ p53a)or 14A-M2 (construct expresses GFP and $\Delta 40$ p53a) and followed up with glucose starvation. Our results suggest that after $8 \mathrm{~h}$ of glucose deprivation in pEGFP transfected cells there is an apparent increase in $4 n$ (and the intermediate $2 n-4 n)$ population after $8 \mathrm{~h}$ and the reverse at $24 \mathrm{~h}$, irrespective of whether SMAR1 is knocked down or not. Interestingly this change at 8-h deprivation is absent in 
$\triangle 40$ 53a-transfected H1299-S3 cells in glucose deprivation, preliminarily suggesting a correlation of $\triangle 40 p 53 a$ and S-phase duration in glucose deprivation that is contingent on SMAR1 levels.
Next, we investigated whether deprivation-induced induction of p53 and $\triangle 40 p 53$ levels is reversible. After $8 \mathrm{~h}$ of glucose deprivation, H1299 (Figure 5i) and A549 cells (Figure 5i) were replenished with a medium containing glucose. In H1299 cells,

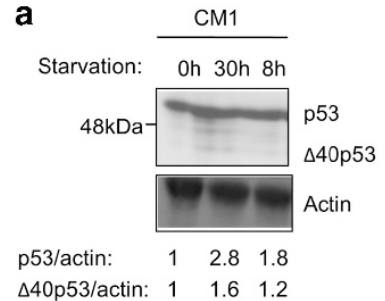

b

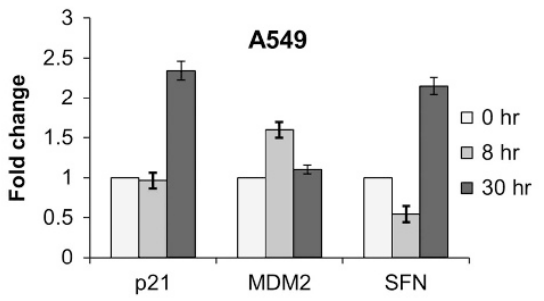

d

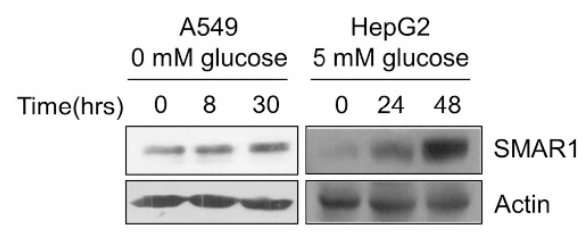

f

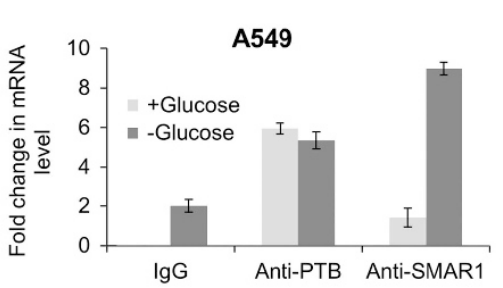

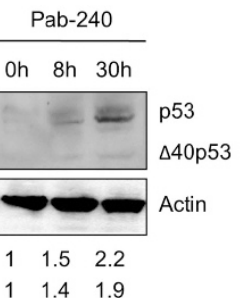

c

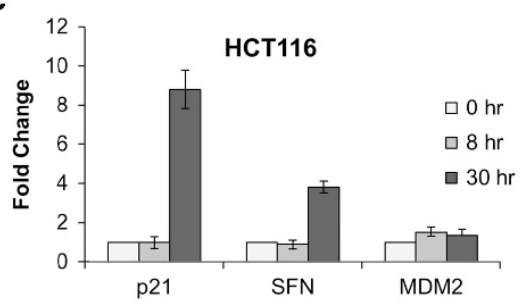

e

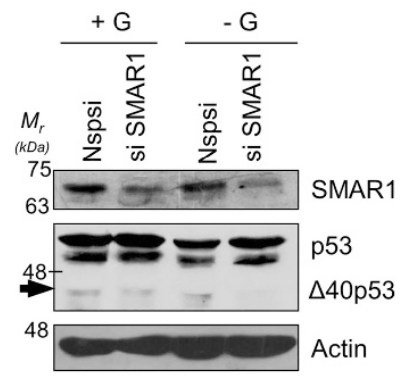

g

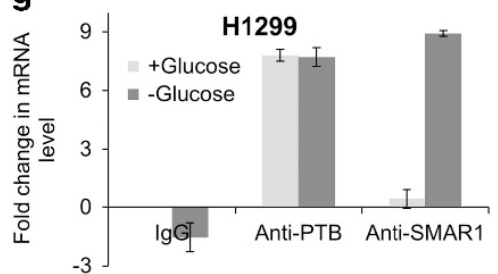

Figure 5 Physiological relevance of glucose deprivation on SMAR1-p53 IRES association. (a) Western blot of A549-cell extracts after indicated duration of glucose starvation, blotted with CM1 (left panel) or Pab240 antibody (right panel). (b,c) Quantitative PCR of $p 21, m d m 2$ and SFN mRNA levels normalized to GAPDH in A549 cells (b) and HCT116 cells (c) following 0,8 and $30 \mathrm{~h}$ of glucose deprivation. (d) Western blot of A549-and HepG2-cell extracts showing the expression pattern of SMAR1 in a time-dependent manner post-glucose deprivation. Glucose was deprived for indicated time in hours and the cells were harvested at the given time points. (e) Western blot analysis of A549-cell extracts transfected with non-targetting (Nsp) or SMAR1 siRNA for $96 \mathrm{~h}$, followed by glucose starvation for $30 \mathrm{~h} . \Delta 40 \mathrm{p} 53$ levels are indicated by an arrow. (f) Reverse transcriptase-quantitative PCR analysis of RNA extracted from ribonucleoprotein complexes immunoprecipitated from non-starved or 8-h glucose-starved A549 cells using antiSMAR1, anti-PTB antibodies or lgG-isotype control. Primers corresponding to 1-251 region of p53 RNA were used. Results represented as fold change over and above RNA immunoprecipitated from non-starved cells with $\mathrm{lgG}$ control antibody. (g) Reverse transcriptase-quantitative PCR analysis of RNA extracted from ribonucleoprotein complexes immunoprecipitated from non-starved or 8-h glucose-starved H1299 cells transfected with GFP-hp-5'UTR-p53-bicistronic mRNA using anti-SMAR1, anti-PTB antibodies or lgGisotype control. Primers corresponding to 1-251 region of p53 RNA were used. Results represented as fold change over and above RNA immunoprecipitated from non-starved cells with IgG control antibody. (h) FACS analysis of cell populations in G1, S or G2-M phases in H1299-NS and H1299-S3 cells. The cells were transfected with 14A (top row), 14A-M2 (middle row) or pEGFP (bottom row). Cell cycle was arrested by double-thymidine treatment, then cells were glucose starved for $0,4,8,12,24$ and $30 \mathrm{~h}$ and harvested at these time points with corresponding unstarved control cells. (i) Glucose replenishment (rescue) for 12 and $24 \mathrm{~h}$ following $8 \mathrm{~h}$ of glucose deprivation in $\mathrm{H} 1299$ cells transfected with pGFP-hp-p53-5'UTR-cDNA plasmid. Western blots depict SMAR1, p53, $\Delta 40$ p53 and actin levels. Graphs represent lane-wise densitometric analysis. (j) Glucose replenishment (rescue) for 12 and $24 \mathrm{~h}$ following $8 \mathrm{~h}$ of glucose deprivation in A549 cells. Western blots depict endogenous p53 and $\Delta 40 \mathrm{p} 53$ (shown by an arrow) as well as SMAR1 and actin levels. Graphs represent lane-wise densitometric values. (k) Quantitative PCR for levels of p53-target mRNAs p21/Cip1 (CDK-interacting protein1), SFN (stratifin alias 14-3-3б), Bax (Bcl-2 associated X), TIGAR (TP53-induced glycolysis and apoptosis regulator), PIDD (P53-induced DNA damage) and Mdm2 (murine double minute 2) in H1299 cells transfected with pGFP-hp-p53-5'UTR-cDNA plasmid, starved of glucose for $8 \mathrm{~h}(8 \mathrm{~h})$ and then rescued by glucose replenishment for $12 \mathrm{~h}(8 \mathrm{~h} / 12 \mathrm{~h})$ and $24 \mathrm{~h}(8 \mathrm{~h} / 24 \mathrm{~h})$. Results represented as fold change in mRNA levels compared to non-starved, transfected cells, $n=3$ 
h
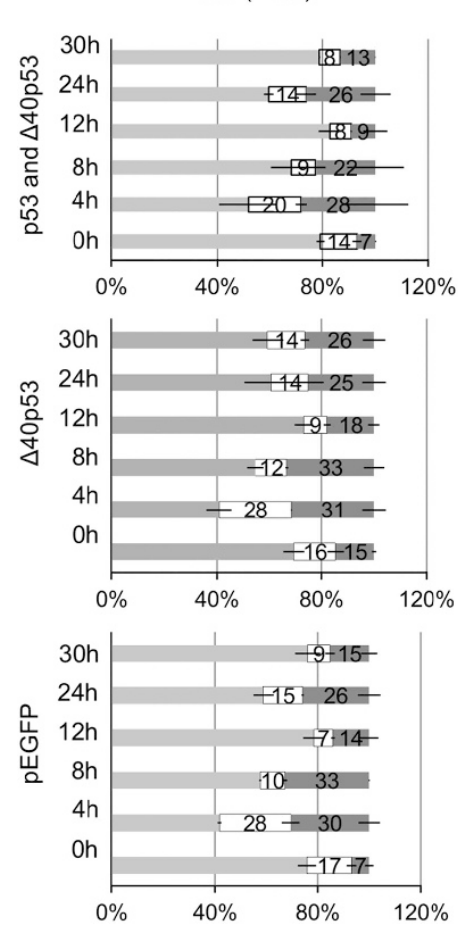

i

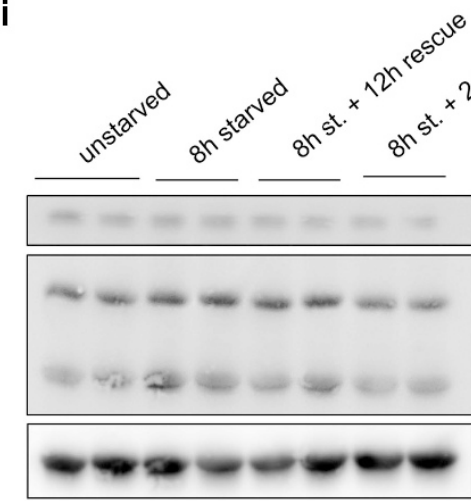

$\begin{array}{llllllll}1 & 2 & 3 & 4 & 5 & 6 & 7 & 8\end{array}$

j

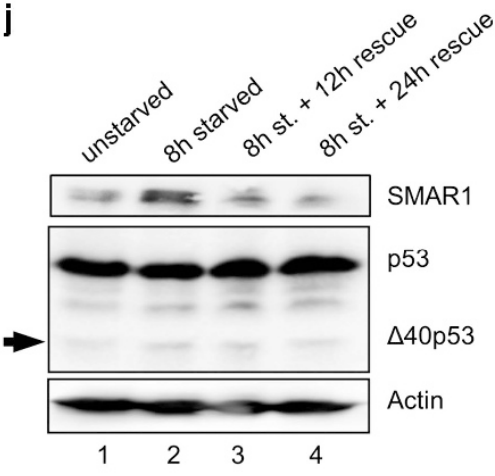

Figure 5 Continued
NS (-Glu)
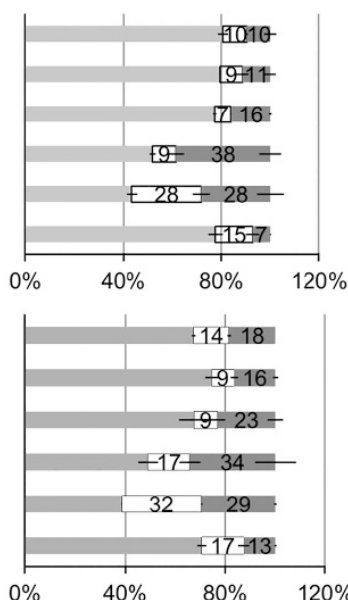

S3 (+Glu)
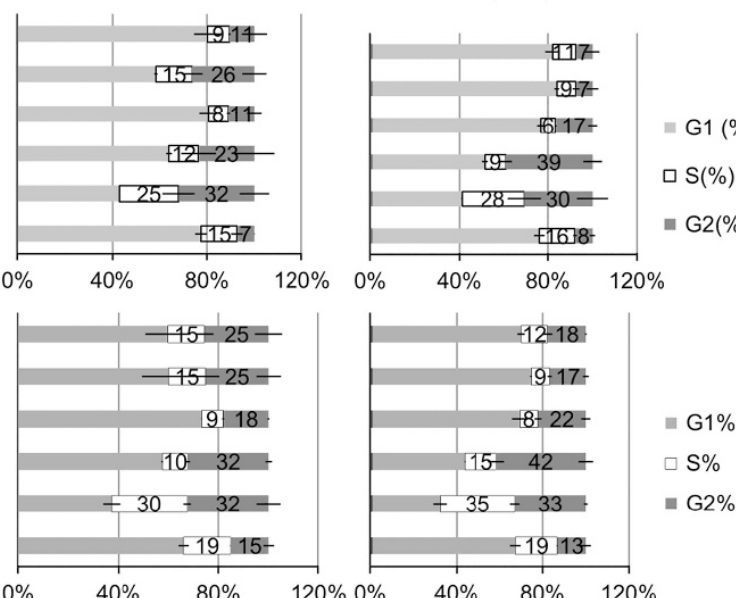

S3 (-Glu)

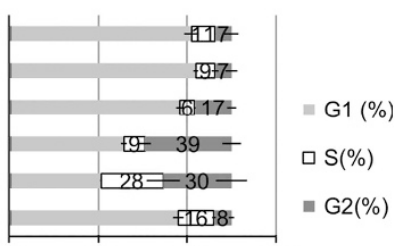

G1\%

$\mathrm{G} 2 \%$
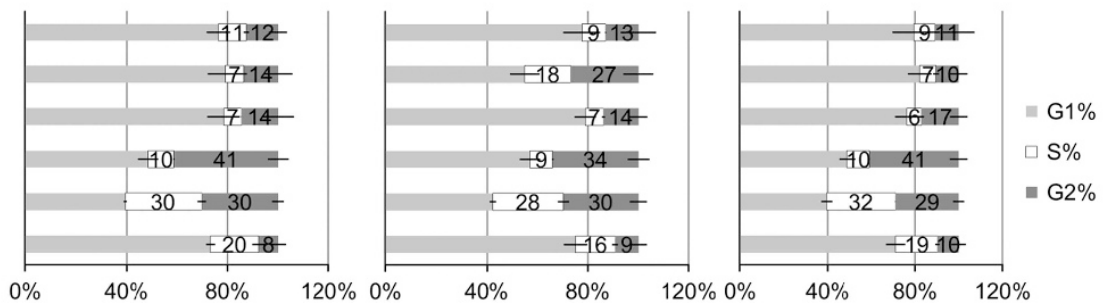

Densitometric analysis

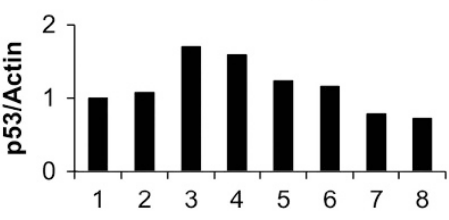

p53

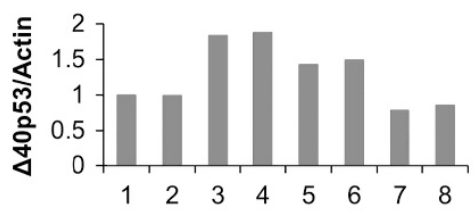

Densitometric analysis
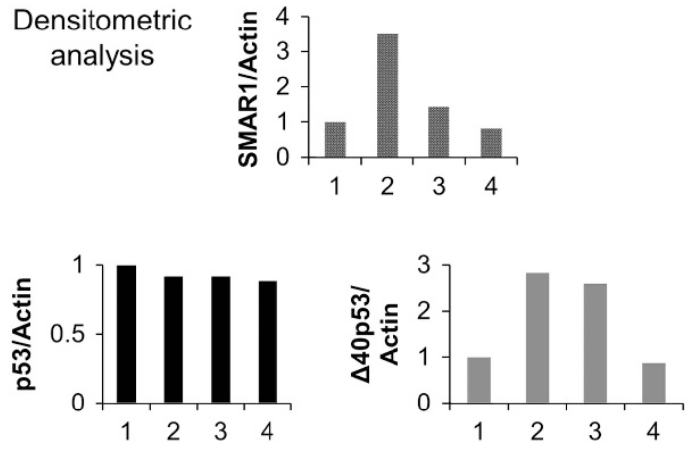

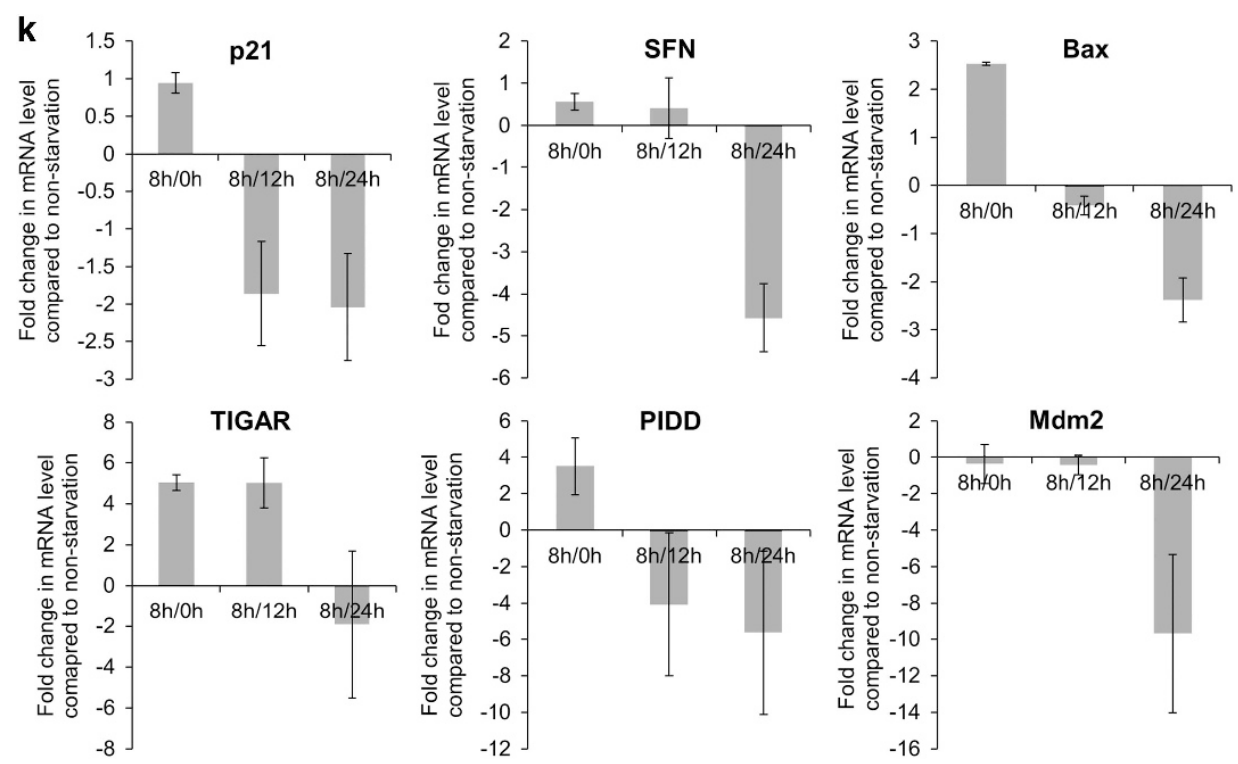

Figure 5 Continued

IRES-driven expression of p53 isoforms from 14A plasmid returned to normal after $24 \mathrm{~h}$ of rescue with replenished glucose (Figure 5i). In A549 cells, endogenous levels of $\triangle 40$ p53 (IRES driven) and SMAR1 increased on deprivation and returned to basal levels on $24 \mathrm{~h}$ of rescue (Figure $5 \mathrm{j}$ ). The steady-state-mRNA levels of six p53 transcription targets were checked in H1299 cells transfected with pGFP-hp-p53-5'UTR cDNA (Figure $5 \mathrm{k}$ ). There was an increase in levels of all the mRNAs, except Mdm2 on 8 h of glucose deprivation. However, on rescue, levels of $p 21$ and SFN (cell-cycle arrest) as well as Bax and PIDD (pro-apoptotic) decreased; whereas TIGAR (glycolysis and apoptosis regulator) remained high after $8 \mathrm{~h}$ of rescue and decreased only after $24 \mathrm{~h}$ of rescue. Interestingly, Mdm2 levels were not affected significantly until $24 \mathrm{~h}$ of rescue, when it decreased significantly compared to nonstarvation (Figure 5k).

The effect of starvation on p53 and $\Delta 40$ p53 was investigated in vivo. Wild-type as well as SMAR1 transgenic mice were starved for 0,12 and $24 \mathrm{~h}$. In the liver, there was a marked increase in SMAR1 levels $24 \mathrm{~h}$ post deprivation (Figure $6 \mathrm{a}$, lanes 5 and 6) that corresponded to an increase in the levels of p44 protein (mouse $\Delta 40$ p53). This was also evident in the thymus (Figure $6 \mathrm{~b}$, lanes 5 and 6 ). In the liver from SMAR1 transgenic mice, the increase in SMAR1 was more evident $12 \mathrm{~h}$ post deprivation with a corresponding increase in $\triangle 40 \mathrm{p} 53$ at this time point (Figure 6a, lanes 9 and 10). The results, however, were more heterogeneous in the thymus from these SMAR1 transgenic mice (Figure 6b, lanes 7-12). A rescue experiment was performed in WT mice, wherein after $24 \mathrm{~h}$ of starvation, these were fed ad libitum for a further 12 and $24 \mathrm{~h}$. Liver lysates from 12 and $24 \mathrm{~h}$ 'rescued' mice showed decrease in the levels of SMAR1, p53 and, to a lesser extent, p44 (mouse $\Delta 40$ p53) protein levels compared to starved mice. The mRNAs of p53 targets, p21 and Mdm2 displayed corroborating changes in their levels, returning to normal (non-starved) levels after $24 \mathrm{~h}$ of rescue. Blood glucose levels in both the wild-type and SMAR1 transgenic mice drop by about 20 and $40 \%$ after 12 and $24 \mathrm{~h}$ of starvation, respectively and are restored to normal levels after $12 \mathrm{~h}$ of feeding (Supplementary Figure S18).

\section{Discussion}

During translational control of p53 mRNA, levels of full-length p53 are predominantly regulated by cap-dependent translation initiation and IRES functions more as a back-up in stress, when cap-dependent translation declines. However, for $\triangle 40 p 53$ such regulation is solely IRES dependent. We report here that glucose deprivation in cultured mammalian cells induces p53 IRES activities. Earlier studies have shown that glucose starvation induces p53 protein levels in an AMPactivated protein kinase-dependent manner. ${ }^{42,43}$ In addition, it was shown that PPAR gamma coactivator 1 alpha (PGC-1a) binds to p53 and modulates its transactivation function on glucose starvation. ${ }^{44}$ p53 IRESs are known to be inducible by ER and genotoxic stress, oncogene overexpression and G2-M arrest. The current study is the first to report that p53 IRESs are sensitive to any form of nutrient depletion. Both the IRES modules of $p 53$ mRNA were seen to be induced on glucose starvation and higher steady-state levels of p53 and $\Delta 40$ p53 could be abrogated on treatment with translation-blocker cycloheximide even in glucose depletion, further confirming the role of IRES-mediated translation in p53 mRNA under such stress. There is also a greater turnover of p53 isoforms on glucose deprivation, evident on cycloheximide treatment also. The striking feature was a complete abrogation of induced p53 isoform levels on glucose deprivation because of arrested translation with cycloheximide treatment, hence for the current study we focussed on IRES-mediated enhancement of translation of p53 isoforms on glucose deprivation. Glucose starvation has been observed as a form of ER stress because similar to this stress, depleting glucose in a medium of cultured cells results in increased elF2a phosphorylation. ${ }^{39}$ p53-MDM2 protein interactions are well documented in the 
a

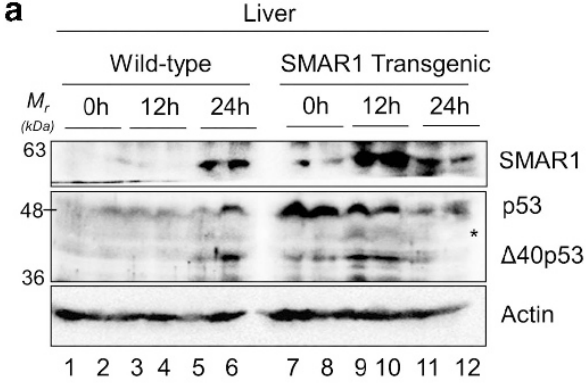

b

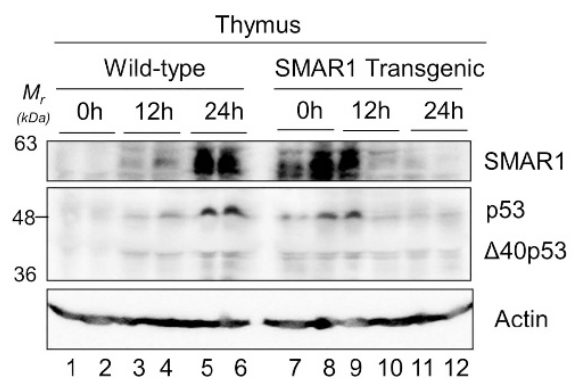

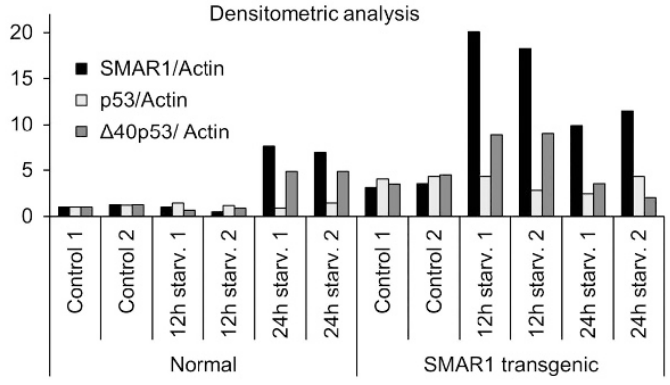

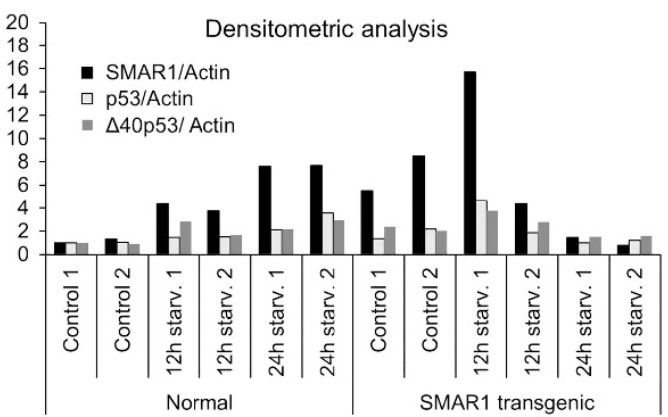

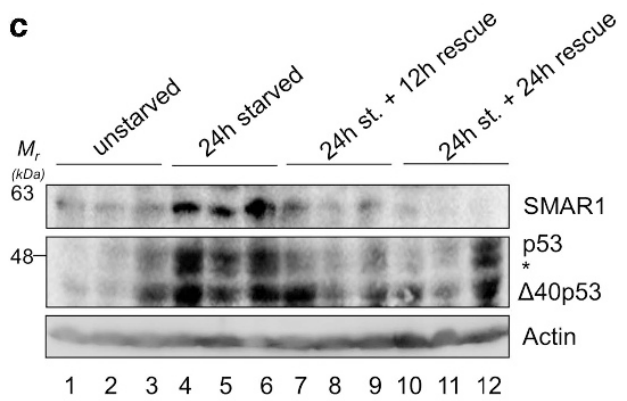

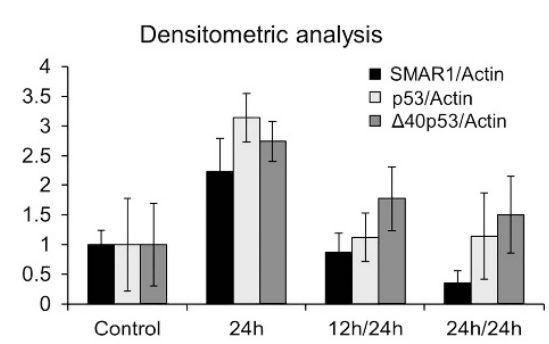

d
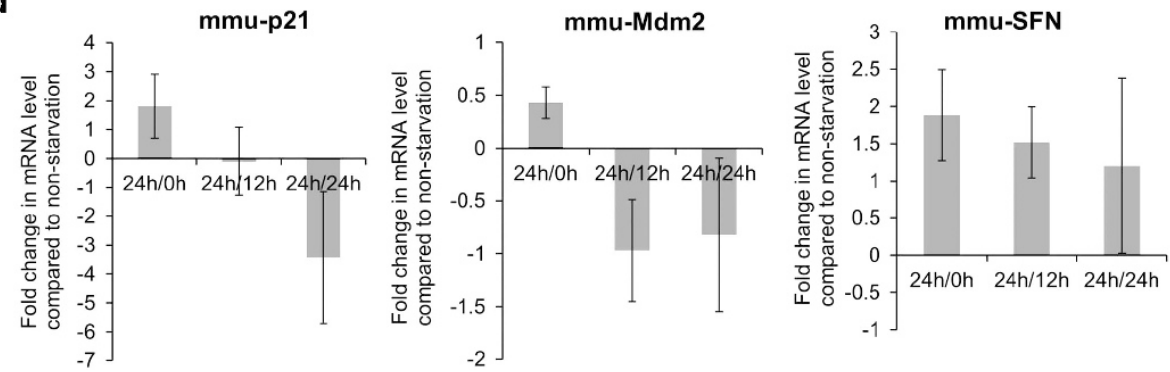

Figure 6 Starvation induces levels of SMAR1, p53 and $\triangle 40 \mathrm{p} 53$ in vivo and this effect is reversible on withdrawal of starvation. Western blot of tissue extracts of liver (a) or thymus (b) from wild-type and SMAR1 transgenic mice at 0, 12 and $24 \mathrm{~h}$ of starvation, in duplicates, probed for SMAR1 (upper panel), p53 and $\Delta 40 \mathrm{p} 53$ (middle panel) and actin (lower panel). Graphs show lane-wise densitometric analysis of SMAR1, p53 and $\Delta 40$ p53 levels normalized to actin, $n=4$. '*' represents non-specific band. (c) Rescue experiment on starvation withdrawal for 12 and $24 \mathrm{~h}$ following $24 \mathrm{~h}$ of dietary starvation. Western blot of tissue extracts of the liver from wild-type mice probed for SMAR1 (upper panel), p53 and $\Delta 40$ p53 (middle panel) and actin (lower panel). Graphs show lane-wise densitometric analysis of SMAR1, p53 and $\Delta 40$ p53 levels normalized to actin, $n=3$.

“' represents non-specific band. (d) Quantitative PCR for levels of p53-target mRNAs p21/Cip1 (CDK-interacting protein1), SFN (stratifin alias 14-3-3 6 ) and Mdm2 (murine double minute 2) in wild-type mice liver, starved of glucose for $12 \mathrm{~h}(12 \mathrm{~h})$ and then rescued by starvation withdrawal for $12 \mathrm{~h}(12 \mathrm{~h} / 12 \mathrm{~h})$ and $24 \mathrm{~h}$ (12 $\mathrm{h} / 24 \mathrm{~h})$. Results represented as fold change in mRNA levels compared to liver from non-starved mice, $n=3$. mmu: Mus musculus

scientific literature. ${ }^{40,45} \mathrm{MDM} 2$ protein also binds to the coding region of p53 IRES RNA and promotes translation of the full-length $\mathrm{p} 53$ and the alternatively translated product $\triangle 40$ p53. ${ }^{12,35}$ p53 is also known to have RNA re-annealing properties, binding to the $5^{\prime}$ UTR of its own mRNA, ${ }^{34}$ as well as of Cdk $4{ }^{46}$ and FGF2. ${ }^{47,48}$ Recent reports showed that SMAR1 forms a ternary complex with p53-MDM2, in which MDM2 binds to residues 17-26 of p53 and SMAR 1 binds to residues 14-16 of p53, with a simultaneous interaction of SMAR1 and MDM2. ${ }^{37}$

We report that SMAR1 is able to bind to p53 (1-251) IRES directly and specifically in the in vitro studies; ex vivo 
immunoprecipitation experiments serve in confirming this association. SMAR1 was identified as a novel DNA-binding protein from murine thymocyte expression library screen that was associated with matrix attachment region on enhancer regions for genes encoding T-cell receptor $\beta$ chain in murine CD $4^{+} \mathrm{CD}^{+}{ }^{+}$double-positive thymocytes. ${ }^{49}$ SMAR 1 has been implicated in maintaining cellular homeostasis and is a global regulator/modulator of gene expression. ${ }^{37,38,50-54}$ Our recent study showed that SMAR1 is directly linked to translation of both p53 and $\Delta 40$ p53 in normal as well as glucose-deprived conditions. 14-3-30 was demonstrated as a preferential transcriptional target of $\Delta 40 p 53 ., 14$ The downstream effects of $\triangle 40 p 53$ induction on target gene activation, and the resulting biological outcome, have been previously explored. ${ }^{55-57}$ In the current study, using $\triangle 40$ p53-mediated transactivation as a model, we showed that SMAR1 is important for IRESdependent $\triangle 40 p 53$ induction, as well as for the consequent elevation of $14-3-3 \sigma$ mRNA (Figure $2 e$ ). Therefore, activation of p53 IRES by SMAR1 is likely to contribute to $\triangle 40 p 53$ function, probably more than full-length $\mathrm{p} 53$, as translational induction of the shorter isoform has to be through IRES and hence ITAF mediated. Also, p53-mediated transactivation was found to be lesser in case of SMAR1-knockdown cells, largely in both non-starved and starved conditions (Figure 2e). Nuclear-cytoplasmic relocalization of ITAFs is essential for cellular IRES function. ${ }^{58-60}$ We report in the current study a glucose-dependent relocalization of SMAR1, but not PTB, in cultured cells, highlighting the novelty of SMAR1-mediated control in stress. In addition, rescue experiments both ex vivo and in vivo show that the induction of p53 isoform levels on nutrient deprivation is reversible, with these returning to basal levels on nutrient replenishment. The changes in p53 transactivation target mRNAs also largely corroborate this finding.

Deregulations in translational control contribute to each step of cellular transformation and tumor progression, nutrient starvation being a very common stress for the cells located inside non-vascularized tumors. ${ }^{61}$ Activation of p53 IRESs on glucose deprivation provides a new regulatory aspect to the field of translational control of p53 mRNA, suggesting critical function of the p53 isoforms in these conditions in terms of cell survival and stress tolerance.

\section{Materials and Methods}

Plasmid constructs. Dual-luciferase constructs of the p53 (1-251) IRES, first (1-134) IRES, second (135-251) IRESs, ${ }^{3,8}$ VEGF and HIF1 $\alpha$ IRESs (kind gifts from Professor Greg Goodall, Centre of Cancer Biology, Australia and Professor Annapoorni Rangarajan, MRDG, IISc) and HCV IRES ${ }^{62}$ were used in quantitative bicistronic assays. WWP luciferase (a kind gift from Professor Kumaravel Somasundaram, IISc) was used for measuring p53-dependent transactivation, CMV-Renilla-luciferase (Promega, Madison, WI, USA) constructs were used to normalize transfection efficiency. GFP-p53-bicistronic constructs used were pGFPhp-p53-5'UTR-cDNA-containing initiator ATGs for both p53 and $\triangle 40 p 53$ (a kind gift from Professor Robin Fahraeus, INSERM, France), pGFP-hp-p53-5'UTR-(A252G/ T253C/G254T) cDNA with a functional initiator ATG for p53 only, and pGFP-hp-p535'UTR(A135T) CDNA with a functional initiator ATG for $\Delta 40$ p53 only. pSV40- $\beta$ galactosidase (Promega, Madison, WI, USA) was used as a control for transfection efficiency as well as cap-dependent translation. shRNA-mediated knockdown of SMAR1 was through pGIPZ-shSMAR1(S3) construct, pGIPZ-NS construct expressed non-targeting shRNA. $\triangle$ IRES- $\triangle 40 p 53$ construct was used for capdependent expression of $\Delta 40 \mathrm{p} 53$ (a kind gift from Professor Robin Fahraeus,
INSERM, France and Professor Adi Kimchi, Weizmann Institute of Science, Israel). pCMV-3XFLAG-SMAR1 was used as described earlier. ${ }^{53}$

Cell lines, transfections, glucose deprivation and drug treatment. $\mathrm{H} 1299, \mathrm{HCT} 116-\mathrm{p} 53^{+/+}$, A549 and HepG2 cells were maintained in DMEM (SigmaAldrich, St. Louis, MO, USA) with 10\% fetal bovine serum (Biological Industries, Beit Haemek, Israel). For luciferase assays or western blots, $70 \%$ confluent monolayer of $\mathrm{H} 1299$ or A549 were transfected with various bicistronic luciferase constructs or cDNA plasmids using Lipofectamine 2000 (Invitrogen, Life Technologies, Carlsbad, CA, USA) in Opti-MEM (Invitrogen). Four hours later, the medium was replaced with DMEM (with antibiotic) and 10\% FBS. At the desired time point, the cells were harvested and processed as required. For glucose deprivation, cells were washed twice in DMEM-minus glucose and maintained in the same medium for the desired duration. For establishing cell populations with stable expression of SMAR1 or nontargeting shRNA, corresponding pGIPZ DNA constructs were transfected into $\mathrm{H} 1299$ cells. After $24 \mathrm{~h}, 2-\mu \mathrm{g} / \mathrm{ml}$ puromycin was added in the medium and this concentration was maintained for the next $48 \mathrm{~h}$. Then the pooled-puromycinresistant cells were passaged two times in $1-\mu \mathrm{g} / \mathrm{ml}$ puromycin and SMAR1 knockdown validated by immunoblotting. For all subsequent experiments, pooledantibiotic-resistant H1299-NS and H1299-S3 cells were maintained in $1-\mu \mathrm{g} / \mathrm{ml}$ puromycin. For DNA-damage induction, H1299-NS and S3 cells were treated with $2-\mu \mathrm{M}$ doxorubicin for $16 \mathrm{~h}$.

siRNA transfection. The employed siRNA sequence against SMAR1 was 5'-UAACCCUGAGAUGCGGGUA-3'. As a control for silencing, a siCONTROL non-targeting siRNA \#5 (Dharmacon, Thermo Scientific, Waltham, MA, USA) was used in the experiments in a similar manner. Co-transfection of siRNA with various plasmid constructs was performed in monolayer $\mathrm{H} 1299, \mathrm{HCT} 116-\mathrm{p} 53^{+/+}$or A549 cells using Lipofectamine 2000 (Invitrogen) transfection reagent in Opti-MEM (Invitrogen). Forty-eight or $96 \mathrm{~h}$ post-transfection the cells were harvested and the extracts were used for dual-luciferase assays or for western blot analysis.

Western blot analysis. Protein concentrations of the extracts were assayed by Bradford (Bio-Rad, Hercules, CA, USA) and equal amounts of cell extracts were resolved in SDS-PAGE, 12\% and transferred to nitrocelluose membrane (SigmaAldrich). Samples were then analyzed by western blotting using rabbit-raised CM-1 antibody (kind gift from Professor Robin Fahraeus, INSERM), anti-SMAR1 antibody (Abcam, Cambridge, UK), mouse-raised D01 and Pab240 antibodies (Santa Cruz Biotechnology, Dallas, TX, USA) or rabbit-raised anti-GFP antibody (IMG5127, Imgenex, Bhubaneswar, Odisha, India) followed by secondary antibody (horseradish peroxidase-conjugated anti-rabbit IgG; Sigma-Aldrich). Mouse-monoclonal anti- $\beta$ actin antibody (Sigma-Aldrich) was used as a control for equal loading of total cell extracts. Antibody complexes were detected using the Immobilon Western systems (EMD Millipore, Billerica, MA, USA).

Dual-luciferase assay. Renilla- and firefly-luciferase activities were measured using the dual-luciferase reporter assay system (Promega), according to the manufacturer's protocol, by using TD20/20 Luminometer (Turner BioSystems, Promega).

Beta-galactosidase assay. RIPA lysates from pSV40- $\beta$-galactosidasetransfected cells were used for the colorimetric assay. To $0.1-\mathrm{M}$ sodium phosphate buffer ( $82 \% 0.1-\mathrm{M} \mathrm{Na}_{2} \mathrm{HPO}_{4}$ and $18 \% \quad 0.1-\mathrm{M} \mathrm{NaH}_{2} \mathrm{PO}_{4}$ ), total-protein normalized volumes of RIPA lysates were added along with $0.1-\mathrm{M} \mathrm{MgCl}_{2}, \quad 4.5-\mathrm{M}$ $\beta$-mercaptoethanol and $4-\mathrm{mg} / \mathrm{ml}$ o-nitrophenyl- $\beta$,D-galactopyranoside substrate; reactions were incubated in $37^{\circ} \mathrm{C}$ for $30 \mathrm{~min}$. After quenching with $1-\mathrm{M}$ sodium carbonate solution $\mathrm{A}_{420 \mathrm{~nm}}$ was measured in a spectrophotometer.

Caspase assay. Eight thousand H1299 cells were seeded per well in 96-well plates $16 \mathrm{~h}$ prior to transfection. These were transfected with a total of $15-\mathrm{ng}$ DNA per well and the medium was changed after $6 \mathrm{~h}$. After $48 \mathrm{~h}, 50 \mu \mathrm{l}$ of caspase $3 / 7 \mathrm{Glo}$ reagent (Promega) was added per well, incubated at room temperature for $3 \mathrm{~h}$ and then luminescence was measured in Turner BioSystems plate reader using the corresponding protocol.

RNA isolation and real-time PCR. Total RNA was isolated from $\mathrm{H} 1299$, A549 or HCT116 cells using TRI reagent (Sigma-Aldrich) as per manufacturer's protocol, treated with 10 units of DNase per sample and extracted by phenolchloroform method. For RNA isolation from mice livers, a part of the organ was 
suspended in TRI reagent (Sigma-Aldrich) and 200- $\mu \mathrm{g} / \mathrm{ml}$ glycogen, homogenized by handheld Down's homogenizer (Sigma-Aldrich) by 50 strokes on ice and then manufacturer's protocol was followed as usual. For real-time PCR, first-strand cDNA was synthesized using oligo-(dT) ${ }_{18}$ primer (Thermo Scientific) using RevertAid RT enzyme (Thermo Scientific) from 2- $\mu \mathrm{g}$ RNA. Reaction was set up with $2 \mu$ of $1: 5$ diluted CDNA using DyNAmo qPCR kit (Thermo Scientific) that uses SYBR Green chemistry as per manufacturer's instructions on $\mathrm{ABI}$ Prism $7900 \mathrm{HT}$ machine (Applied Biosystems, Life Technologies) or ABI ViiA7 machine (Applied Biosystems, Life Technologies). Data were analyzed using SDSv2.3 software (Applied Biosystems, Life Technologies) or ViiA7 RUO software (Applied Biosystems, Life Technologies). The results were calculated by the comparative $\Delta \Delta C_{t}$ method. The primer sequences are as follows:

p53 Forward: 5'-TGGGCTTCTTGCATTCTGG-3', p53 reverse: 5'-GCTGTGACT GCTTGTAGATGGC-3'; p21 forward: 5'-CCTCAAATCGTCCAGCGACCTT-3'; p21 reverse: 5'-CATTGTGGGAGGAGCTGTGAAA-3'; BAX forward: $5^{\prime}$-GCCCTTTTG CTT CAGGGTTT-3'; BAX reverse: 5'-TCCAATGTCCAGCCCATGAT-3'; PIDD forward: 5'-CGAGCCCTCTGACACGGT-3'; PIDD reverse: 5'-AGAAGGACACCTGG CCCC-3'; SFN forward (14-3-3 $\sigma$ ): 5'-TGAGAACTGGACAGTGGCAG-3'; SFN (14-3-3 $\sigma$ ) Reverse: 5'-GAGGAAACATGGTCACACCC-3'; MDM2 forward: 5'-ATCTTGGCCAG TATATT ATG-3'; MDM2 reverse: 5'-GTTCCTGTAGATCATGGTAT-3'; TIGAR forward: 5'-CTGACTGAAACTCGCTAAGG-3'; TIGAR reverse: 5'-CAGAACTAGCAGAG GA GAGA-3'; actin forward: 5'-TCACCCACACTGTGCCCATCTACGA-3'; actin reverse: $5^{\prime}$-TGAGGTAGTCAGTCAGGTCCC-3'; mmu-p21 forward: $5^{\prime}$-CGGTGGA ACTTTGACTTCGT-3'; mmu-p21 reverse: 5'-GAGTGCAAGACAGCGACAAG-3'; mmu-Mdm2 forward: 5'-AGATTCCAGCTTCGGAACAA-3'; mmu-Mdm2 reverse: 5'-ACACAATGTGCTGCTGCTTC-3'; mmu-SFN forward: 5'-GAAACCTGCTTTCC GTAGCTTA-3'; mmu-SFN reverse: 5'-TCTGAGCTCGGTCTCTACCTTC-3'; mmuActin forward: 5'-CGGTTCCGATGCCCTGAGGCTCTT-3'; mmu-actin reverse: 5'-CGTCACACTTCATGATGGAATTGA-3'.

Immunofluorescence staining. For immunofluorescence staining, $\mathrm{H} 1299$ cells were grown on coverslips for $14 \mathrm{~h}$ followed by glucose deprivation for $4,8,17$ and $30 \mathrm{~h}$. At each time point, cells on coverslips were washed twice with 1x PBS and fixed by $4 \%$ formaldehyde at room temperature for $20 \mathrm{~min}$. After permeabilization by $0.1 \%$ Triton $\mathrm{X}-100$ for $2 \mathrm{~min}$ at room temperature, cells were incubated with $4 \% \mathrm{BSA}$ at $37^{\circ} \mathrm{C}$ for $1 \mathrm{~h}$ followed by incubation with rabbit-raised anti-SMAR1 (Abcam) antibody or mouse-raised anti-PTB antibody (Calbiochem, White House Station, NJ, USA) for $16 \mathrm{~h}$ at $4{ }^{\circ} \mathrm{C}$ and then detected by Alexa-488conjugated anti-rabbit or Alexa-633-conjugated anti-mouse secondary antibody for $30 \mathrm{~min}$ (Invitrogen). Images were acquired using Zeiss confocal microscope and image analysis was done using LSM Image browser (Zeiss, Oberkochen, Germany).

FACS analysis. For FACS analysis, the asynchronous monolayer of $\mathrm{H} 1299$ cells was trypsinized, washed with $1 \times$ PBS and fixed in $70 \%$ ethanol at $4{ }^{\circ} \mathrm{C}$. Fixed cells were treated with $50 \mu \mathrm{g}$ of RNase A (Thermo Scientific) at $37^{\circ} \mathrm{C}$ for $60 \mathrm{~min}$ and then stained with $20-\mathrm{ng} / \mathrm{ml}$ propidium iodide (Sigma-Aldrich) at $37^{\circ} \mathrm{C}$ for $30 \mathrm{~min}$. Stained cells were analyzed in FACSCantoll (BD Biosciences) cell analyzer using FACS Diva 2.0 software (BD Biosciences).

Immunoprecipitation of RNP complexes in vivo. GFP- $h p-5{ }^{3}$ UTR-p53bicistronic mRNA was synthesized from Xhol linearized pGFP-hp-p53-5'UTR-cDNA plasmid using RiboMax kit (Promega) as per manufacturer's instructions. H1299 cells at $85-90 \%$ confluence $16 \mathrm{~h}$ post-seeding were transfected with these RNAs. After $4 \mathrm{~h}$, no-glucose DMEM with 10\% FBS was added to the experimental set of cells. After another $8 \mathrm{~h}$, cells were lysed with polysome lysis buffer (100-mM KCl, 5$\mathrm{mM} \mathrm{MgCl}_{2}, 10-\mathrm{mM}$ HEPES at pH 7.0, 0.05\% NP-40, 1-mM DTT, 100-U/ml RNasin and $1 \%$ protease inhibitor cocktail). Similarly, untransfected A549 cells were glucose deprived for $8 \mathrm{~h}$, no deprivation was employed for control A549 cells and after $8 \mathrm{~h}$ cells were lysed with polysomal lysis buffer. Supernatants were pre-cleared with Fast-Flow protein-G sepharose beads (Sigma-Aldrich) for $30 \mathrm{~min}$ at room temperature. Pre-cleared lysates containing equal total protein $(500 \mu \mathrm{g})$ were incubated with anti-SMAR1, anti-PTB- (Calbiochem) or rabbit lgG (Sigma-Aldrich) saturated protein-G sepharose beads overnight at $4{ }^{\circ} \mathrm{C}$. RNP complexes conjugated to antibody-bound beads were spun down at 8000 r.p.m. for 2 min, washed four times in ice-cold polysomal lysis buffer and spun down similarly. RNP complexes were precipitated followed by proteinase-K (Promega) treatment for $30 \mathrm{~min}$ at $55^{\circ} \mathrm{C}$. RNA was extracted using TRI reagent (Sigma-Aldrich) as per manufacturer's protocol and treated with DNase-I (Promega) at $37^{\circ} \mathrm{C}$ for $20 \mathrm{~min}$. Finally, with phenol-chloroform-precipitated RNA, RT-PCR was performed using IRES-specific reverse primer and RevertAid reverse transcriptase (Thermo Scientific). CDNA was used for quantitative PCR using IRES-specific primers and PCR products resolved in $2 \%$ agarose gel. The primer sequences are as follows: p53-10-27-F-IP: 5'-ACCGTCCAGGGAGCAGGT-3', p53-238-251-R-IP: 5'-TGCTTGGGACGGCA -3'. Input was normalized using the values obtained in RNA isolated from $10 \%$ input lysate.

In vivo experiments in mice. A total of 24 eight-week-old female C57BL/6 mice (12 WT and 12 transgenic; for SMAR1) ${ }^{63}$ were employed in the experiment. Three time points were used, for example, $0 \mathrm{~h}$ (control), $12 \mathrm{~h}$ (of starvation) and $24 \mathrm{~h}$ (of starvation). At each time point four mice per experimental set were killed and the required tissues (liver and thymus) were isolated. For the rescue experiment, a total of 12 WT mice were employed, three each for control, 24-h starvation, 24-h starvation/12-h rescue and 24-h starvation/24-h rescue batches. The tissues were first washed in ice-cold 1x PBS and were finely minced using a scissor and forceps, on ice. In total, $30 \mathrm{mg}$ of the minced tissue sample was suspended in 1x RIPA buffer and was subjected to sonication ( $15 \mathrm{~s} / 15 \mathrm{~s}$; pulse/pause) at high intensity for a total time of $15 \mathrm{~min}$ in a sonication machine (Bioruptor, Diagenode, Denvile, NJ, USA). The samples were then centrifuged at 12000 r.p.m. for $30 \mathrm{~min}$. The supernatant was collected and processed for immunoblotting. For blood glucose level determination, wild-type (C57BL/6) and SMAR1 transgenic (SMAR1Tg) mice were used to set up the experiment. Blood was collected by heart puncture and the serum was isolated. The serum glucose levels were measured by GOD-POD method using a kit (Spinreact, Girona, Spain). The absorbance was measured at $505 \mathrm{~nm}$ in an ELISA plate reader. The levels were then calculated with reference to the standard sample. The graph represents the data of four independent experiments.

In vitro transcription. For mSMAR1-binding analysis of p53 (1-251) IRES, the respective bicistronic plasmid DNA was PCR amplified using T7 promoter sequence-tagged $p 53$ forward primer and specific reverse primer. Amplified DNA was purified using PCR-purification kit (Qiagen, Venlo, The Netherlands) as per manufacturer's instructions. As per manufacturer's instructions the $\alpha^{32} \mathrm{P}$-UTPlabeled RNA probe of 1-251 IRES RNA was synthesised with T7 RNA polymerase and $10 \mu \mathrm{Ci} / \mu \mathrm{l}$ of $\alpha_{-}^{-32} \mathrm{P}$-UTP (NEN, Perkin Elmer, Waltham, MA, USA) and used for UV-crosslinking assays. In addition, 40 units of RNase inhibitor (Promega) were included in each reaction in order to inhibit the activity of contaminating nucleases.

Protein purification. The expression of recombinant mouse SMAR1 was induced by 1-M IPTG for $16 \mathrm{~h}$ in Escherichia coli (BL21 DE3) cells transformed with pET28b-SMAR1. His-tagged protein was purified using $\mathrm{Ni}^{2+}$-nitrilotriacetic acid-agarose (Qiagen) under non-denaturing conditions and eluted with 500-mM imidazole.

UV-induced crosslinking of proteins and RNA. UV-induced crosslinking was carried out as described elsewhere. ${ }^{3}$ Briefly, $\alpha{ }^{3}{ }^{32} \mathrm{P}$-UTP-labeled 1-251 IRES RNA probe was allowed to form complexes with recombinant mSMAR1 at $30^{\circ} \mathrm{C}$ for $25 \mathrm{~min}$ in $1 \mathrm{x}$ RNA-binding buffer and then irradiated with a handheld UV lamp for $20 \mathrm{~min}$. The mixture was treated with $30-\mu \mathrm{g}$ RNase A (Sigma-Aldrich) at $37^{\circ} \mathrm{C}$ for $30 \mathrm{~min}$. The protein-nucleotidyl complexes were electrophoresed on SDS-PAGE, $10 \%$ and analyzed by phosphorimaging.

Electrophoretic mobility shift assay. Conditions for EMSA have been previously described. ${ }^{64} \alpha{ }^{32}$ P-UTP-labeled p53 1-251 IRES (25 fmol) was incubated with 300 and $600 \mathrm{ng}$ of His-SMAR1 protein at $30^{\circ} \mathrm{C}$ for $30 \mathrm{~min}$. Loading dye was added and the protein-nucleotidyl complex was resolved on a $4 \%(60: 1)$ polyacrylamide gel at $4^{\circ} \mathrm{C}$.

Filter-binding assay. The $\alpha^{-32} \mathrm{P}$-labeled corresponding p53 RNAs (1-251 or $1-134$ or $135-251$ regions of p53 IRES) were incubated with increasing concentrations of purified mSMAR 1 at $30^{\circ} \mathrm{C}$ for $20 \mathrm{~min}$ in RNA-binding buffer (5-mM HEPES at pH 7.6, 2- $\mathrm{mM} \mathrm{KCl}, 2-\mathrm{mM} \mathrm{MgCl}_{2}, 3.8 \%$ glycerol, 2-mM DTT and $0.1-\mathrm{mM}$ EDTA) and loaded onto nitrocellulose filters equilibrated again with RNAbinding buffer. The filters were washed four times, dried and the counts retained were measured in a scintillation counter. The graph was plotted with protein concentration (micromolar concentrations) on $x$-axis and percentage of RNA bound as the percentage of counts retained on $y$-axis. 
Statistical analysis. The data were expressed as mean \pm S.D. Statistical significance was determined using two-sided Student's $t$-test. The criterion for statistical significance was $P<0.05\left(^{*}\right)$ or $P<0.005\left(^{* *}\right)$.

\section{Conflict of Interest}

The authors declare no conflict of interest.

Acknowledgements. We thank Professor Robin Fahraeus (INSERM, France) and Profesor Adi Kimchi (Weizmann Institute of Science, Israel) for sharing various p53 cDNA constructs, Professor Greg Goodall (Centre of Cancer Biology, Australia) and Professor Annapoorni Rangarajan (MRDG, IISc) for sharing VEGF and HIF1 $\alpha$ bicistronic constructs and Professor K Somasundaram (MCB, IISC) for sharing the WWP-luciferase construct. We also thank the FACS facility (Division of Biological Sciences, IISc) for the acquisition of the flow-cytometric data. We also thank the present and past SD lab-members for critical discussion of the work. DK, AS and AD were supported by pre-doctoral fellowships from Council of Scientific and Industrial Research, India. This work was supported by a grant from the Department of Biotechnology, India to Sa.D. Sa.D and SC thank JC Bose fellowship from DST, Government of India.

\section{Author contributions}

DK contributed to conception and design of studies, data acquisition, analysis and interpretation and writing the article; AK was involved in generation of mutant constructs and interpretation of corresponding data, co-acquisition of quantitative PCR data, co-acquistion and analysis of FACS data; AD was responsible for acquisition, analysis and interpretation of in vivo data; $R L$ contributed to acquisition, analysis and interpretation of in vitro binding data; AS was involved in acquisition, analysis and interpretation of immunofluorescence data; PR contributed to acquisition, analysis and interpretation of data from cell lines expressing endogenous p53 isoforms; Sr.D was responsible for acquisition of in vitro binding data; and SC and Sa.D contributed to conception and design of studies, data analysis and interpretation and writing the article.

1. Candeias MM. The can and can't dos of p53 RNA. Biochimie 2011; 93: 1962-1965.

2. Halaby MJ, Yang DQ. p53 translational control: a new facet of p53 regulation and its implication for tumorigenesis and cancer therapeutics. Gene 2007; 395: 1-7.

3. Grover R, Ray PS, Das S. Polypyrimidine tract binding protein regulates IRES-mediated translation of p53 isoforms. Cell Cycle 2008; 7: 2189-2198.

4. Belin S, Beghin A, Solano-Gonzalez E, Bezin L, Brunet-Manquat S, Textoris $\mathrm{J}$ et al. Dysregulation of ribosome biogenesis and translational capacity is associated with tumor progression of human breast cancer cells. PLoS One 2009; 4: e7147.

5. Bourougaa K, Naski N, Boularan C, Mlynarczyk C, Candeias MM, Marullo S et al. Endoplasmic reticulum stress induces $\mathrm{G} 2$ cell-cycle arrest via mRNA translation of the p53 isoform p53/47. Mol Cell 2010; 38: 78-88.

6. Bellodi C, Krasnykh O, Haynes N, Theodoropoulou M, Peng G, Montanaro L et al. Loss of function of the tumor suppressor DKC1 perturbs p27 translation control and contributes to pituitary tumorigenesis. Cancer Res 2010; 70: 6026-6035.

7. Grover R, Sharathchandra A, Ponnuswamy A, Khan D, Das S. Effect of mutations on the p53 IRES RNA structure: implications for de-regulation of the synthesis of $p 53$ isoforms. RNA Biol 2011; 8: 132-142.

8. Ray PS, Grover R, Das S. Two internal ribosome entry sites mediate the translation of p53 isoforms. EMBO Rep 2006; 7: 404-410.

9. Marcel V, Ghayad SE, Belin S, Therizols G, Morel AP, Solano-Gonzalez E et al. p53 acts as a safeguard of translational control by regulating fibrillarin and rRNA methylation in cancer Cancer Cell 2013; 24: 318-330.

10. Su H, Xu T, Ganapathy S, Shadfan M, Long M, Huang TH et al. Elevated snoRNA biogenesis is essential in breast cancer. Oncogene 2014; 33: 1348-1358.

11. Khan D, Sharathchandra A, Ponnuswamy A, Grover R, Das S. Effect of a natural mutation in the $5^{\prime}$ untranslated region on the translational control of p53 mRNA. Oncogene 2013; 32 4148-4159.

12. Candeias MM, Malbert-Colas L, Powell DJ, Daskalogianni C, Maslon MM, Naski N et al. P53 mRNA controls p53 activity by managing Mdm2 functions. Nat Cell Biol 2008; 10: 1098-1105.

13. Sharathchandra A, Lal R, Khan D, Das S. Annexin A2 and PSF proteins interact with p53 IRES and regulate translation of p53 mRNA. RNA Biol 2012; 9: 1429-1439.

14. Weingarten-Gabbay S, Khan D, Liberman N, Yoffe Y, Bialik S, Das S et al. The translation initiation factor DAP5 promotes IRES-driven translation of p53 mRNA. Oncogene 2014; 33: 611-618.

15. Kim DY, Kim W, Lee KH, Kim SH, Lee HR, Kim HJ et al. hnRNP Q regulates translation of p53 in normal and stress conditions. Cell Death Differ 2013; 20: 226-234.

16. Takagi M, Absalon MJ, McLure KG, Kastan MB. Regulation of $\mathrm{p} 53$ translation and induction after DNA damage by ribosomal protein L26 and nucleolin. Cell 2005; 123: 49-63.
17. Chen J, Guo K, Kastan MB. Interactions of nucleolin and ribosomal protein L26 (RPL26) in translational control of human p53 mRNA. J Biol Chem 2012; 287: 16467-16476.

18. Wedeken L, Singh P, Klempnauer KH. Tumor suppressor protein Pdcd4 inhibits translation of p53 mRNA. J Biol Chem 2011; 286: 42855-42862.

19. Zhang M, Zhang J, Chen X, Cho SJ, Chen X. Glycogen synthase kinase 3 promotes p53 mRNA translation via phosphorylation of RNPC1. Genes Dev 2013; 27: 2246-2258.

20. Marr MT 2nd, D'Alessio JA, Puig O, Tjian R. IRES-mediated functional coupling of transcription and translation amplifies insulin receptor feedback. Genes Dev 2007; 21: 175-183.

21. Bruhat $A$, Cherasse $Y$, Chaveroux $C$, Maurin AC, Jousse $C$, Fafournoux $P$. Amino acids as regulators of gene expression in mammals: molecular mechanisms. Biofactors 2009: 35: 249-257.

22. Harding HP, Zhang Y, Zeng H, Novoa I, Lu PD, Calfon M et al. An integrated stress response regulates amino acid metabolism and resistance to oxidative stress. Mol Cell 2003; 11 : 619-633.

23. Zhang P, McGrath BC, Reinert J, Olsen DS, Lei L, Gill S et al. The GCN2 elF2alpha kinase is required for adaptation to amino acid deprivation in mice. Mol Cell Biol 2002; 22: 6681-6688.

24. Fernandez J, Yaman I, Mishra R, Merrick WC, Snider MD, Lamers WH et al. Internal ribosome entry site-mediated translation of a mammalian mRNA is regulated by amino acid availability. J Biol Chem 2001; 276: 12285-12291.

25. Gaccioli F, Huang CC, Wang C, Bevilacqua E, Franchi-Gazzola R, Gazzola GC et al. Amino acid starvation induces the SNAT2 neutral amino acid transporter by a mechanism that involves eukaryotic initiation factor 2alpha phosphorylation and cap-independent translation. J Biol Chem 2006; 281: 17929-17940.

26. Oltean S, Banerjee R. A B12-responsive internal ribosome entry site (IRES) element in human methionine synthase. J Biol Chem 2005; 280: 32662-32668.

27. Ashe MP, De Long SK, Sachs AB. Glucose depletion rapidly inhibits translation initiation in yeast. Mol Biol Cell 2000; 11: 833-848.

28. Cullen PJ, Sprague GF Jr.. Glucose depletion causes haploid invasive growth in yeast. Proc Natl Acad Sci USA 2000; 97: 13619-13624.

29. Gilbert WV, Zhou K, Butler TK, Doudna JA. Cap-independent translation is required for starvation-induced differentiation in yeast. Science 2007; 317: 1224-1227.

30. Sherrill KW, Lloyd RE. Translation of CIAP2 mRNA is mediated exclusively by a stressmodulated ribosome shunt. Mol Cell Biol 2008; 28: 2011-2022.

31. Holcik M, Lefebvre C, Yeh C, Chow T, Korneluk RG. A new internal-ribosome-entry-site motif potentiates XIAP-mediated cytoprotection. Nat Cell Biol 1999; 1: 190-192.

32. Wang G, Miskimins R, Miskimins WK. Regulation of p27(Kip1) by intracellular iron levels. Biometals 2004; 17: 15-24.

33. Cho S, Kim JH, Back SH, Jang SK. Polypyrimidine tract-binding protein enhances the internal ribosomal entry site-dependent translation of p27Kip1 mRNA and modulates transition from G1 to S phase. Mol Cell Biol 2005; 25: 1283-1297.

34. Mosner J, Mummenbrauer T, Bauer C, Sczakiel G, Grosse F, Deppert W. Negative feedback regulation of wild-type p53 biosynthesis. EMBO J 1995; 14: 4442-4449.

35. Yin Y, Stephen CW, Luciani MG, Fahraeus R. p53 stability and activity is regulated by Mdm2-mediated induction of alternative p53 translation products. Nat Cell Biol 2002; 4: 462-467.

36. Grover R, Candeias MM, Fahraeus R, Das S. p53 and little brother p53/47: linking IRES activities with protein functions. Oncogene 2009; 28: 2766-2772.

37. Pavithra L, Mukherjee S, Sreenath K, Kar S, Sakaguchi K, Roy S et al. SMAR1 forms a ternary complex with p53-MDM2 and negatively regulates p53-mediated transcription. J Mo Biol 2009; 388: 691-702.

38. Sinha S, Malonia SK, Mittal SP, Singh K, Kadreppa S, Kamat R et al. Coordinated regulation of p53 apoptotic targets BAX and PUMA by SMAR1 through an identical MAR element. EMBO J 2010; 29: 830-842.

39. Scheuner D, Song B, McEwen E, Liu C, Laybutt R, Gillespie P et al. Translational control is required for the unfolded protein response and in vivo glucose homeostasis. Mol Cell 2001; 7: 1165-1176.

40. Picksley SM, Vojtesek B, Sparks A, Lane DP. Immunochemical analysis of the interaction of p53 with MDM2-fine mapping of the MDM2 binding site on p53 using synthetic peptides. Oncogene 1994; 9: 2523-2529.

41. Singh S, Sreenath K, Pavithra L, Roy S, Chattopadhyay S. SMAR1 regulates free radical stress through modulation of AKR1a4 enzyme activity. Int J Biochem Cell Biol 2010; 42: $1105-1114$.

42. Jones RG, Plas DR, Kubek S, Buzzai M, Mu J, Xu Y et al. AMP-activated protein kinase induces a p53-dependent metabolic checkpoint. Mol Cell 2005; 18: 283-293.

43. Okoshi R, Ozaki T, Yamamoto H, Ando K, Koida N, Ono S et al. Activation of AMP-activated protein kinase induces p53-dependent apoptotic cell death in response to energetic stress. J Biol Chem 2008; 287: 3979-3987.

44. Sen N, Satija YK, Das S. PGC-1alpha, a key modulator of p53, promotes cell survival upon metabolic stress. Mol Cell 2011; 44: 621-634.

45. Momand J, Zambetti GP, Olson DC, George D, Levine AJ. The mdm-2 oncogene product forms a complex with the p53 protein and inhibits p53-mediated transactivation. Cell 1992; 69: $1237-1245$

46. Miller SJ, Suthiphongchai T, Zambetti GP, Ewen ME. p53 binds selectively to the $5^{\prime}$ untranslated region of cdk4, an RNA element necessary and sufficient for transforming growth factor beta- and p53-mediated translational inhibition of cdk4. Mol Cell Biol 2000; 20: 8420-8431. 
47. Gonzalez-Herrera IG, Prado-Lourenco L, Pileur F, Conte C, Morin A, Cabon F et al. Testosterone regulates FGF-2 expression during testis maturation by an IRES-dependent translational mechanism. FASEB J 2006; 20: 476-478.

48. Gonzalez-Herrera IG, Prado-Lourenco L, Teshima-Kondo S, Kondo K, Cabon F, Arnal JF et al. IRES-dependent regulation of FGF-2 mRNA translation in pathophysiological conditions in the mouse. Biochem Soc Trans 2006; 34: 17-21.

49. Chattopadhyay S, Kaul R, Charest A, Housman D, Chen J. SMAR1, a novel, alternatively spliced gene product, binds the scaffold/matrix-associated region at the $\mathrm{T}$ cell receptor beta locus. Genomics 2000; 68: 93-96.

50. Jalota A, Singh K, Pavithra L, Kaul-Ghanekar R, Jameel S, Chattopadhyay S. Tumor suppressor SMAR1 activates and stabilizes p53 through its arginine-serine-rich motif. J Biol Chem 2005; 280: 16019-16029.

51. Singh K, Sinha S, Malonia SK, Bist P, Tergaonkar V, Chattopadhyay S. Tumor suppressor SMAR1 represses IkappaBalpha expression and inhibits p65 transactivation through matrix attachment regions. J Biol Chem 2009; 284: 1267-1278.

52. Pavithra L, Singh S, Sreenath K, Chattopadhyay S. Tumor suppressor SMAR1 downregulates cytokeratin 8 expression by displacing p53 from its cognate site. Int $J$ Biochem Cell Biol 2009; 41: 862-871.

53. Rampalli S, Pavithra L, Bhatt A, Kundu TK, Chattopadhyay S. Tumor suppressor SMAR1 mediates cyclin D1 repression by recruitment of the SIN3/histone deacetylase 1 complex. Mol Cell Biol 2005; 25: 8415-8429.

54. Sinha S, Malonia SK, Mittal SP, Mathai J, Pal JK, Chattopadhyay S. Chromatin remodelling protein SMAR1 inhibits p53 dependent transactivation by regulating acetyl transferase p300. Int J Biochem Cell Biol 2012; 44: 46-52.
55. Maier B, Gluba W, Bernier B, Turner T, Mohammad K, Guise T et al. Modulation of mammalian life span by the short isoform of p53. Genes Dev 2004; 18: 306-319.

56. Ohki R, Kawase T, Ohta T, Ichikawa H, Taya Y. Dissecting functional roles of $p 53$ $\mathrm{N}$-terminal transactivation domains by microarray expression analysis. Cancer Sci 2007; 98 : 189-200.

57. Powell DJ, Hrstka R, Candeias M, Bourougaa K, Vojtesek B, Fahraeus R. Stress-dependent changes in the properties of p53 complexes by the alternative translation product p53/47. Cell Cycle 2008; 7: 950-959.

58. Spriggs KA, Bushell M, Mitchell SA, Willis AE. Internal ribosome entry segment-mediated translation during apoptosis: the role of IRES-trans-acting factors. Cell Death Differ 2005; 12 : 585-591.

59. Lewis SM, Holcik M. For IRES trans-acting factors, it is all about location. Oncogene 2008; 27: $1033-1035$.

60. Komar AA, Hatzoglou M. Cellular IRES-mediated translation: the war of ITAFs in pathophysiological states. Cell Cycle 2011; 10: 229-240.

61. Ruggero D. Translational control in cancer etiology. Cold Spring Harb Perspect Biol 2013; 5 : pii: a012336.

62. Ray PS, Das S. Inhibition of hepatitis C virus IRES-mediated translation by small RNAs analogous to stem-loop structures of the 5'-untranslated region. Nucleic Acids Res 2004; 32: 1678-1687.

63. Kaul-Ghanekar R, Majumdar S, Jalota A, Gulati N, Dubey N, Saha B et al. Abnormal V(D)J recombination of T cell receptor beta locus in SMAR1 transgenic mice. J Biol Chem 2005; 280: 9450-9459.

64. Hellman LM, Fried MG. Electrophoretic mobility shift assay (EMSA) for detecting proteinnucleic acid interactions. Nat Protoc 2007; 2: 1849-1861.

Supplementary Information accompanies this paper on Cell Death and Differentiation website (http://www.nature.com/cdd) 